\title{
EL CINE NORTEAMERICANO EN ESPAÑA: LAS NEGOCIACIONES PARA SU IMPORTACIÓN, 1950-1955*
}

\author{
Pablo León Aguinaga \\ Instituto de Historia, CSIC
}

RESUMEN: Las negociaciones para la importación de películas norteamericanas durante el franquismo fueron objeto de continua fricción. Las autoridades españolas intentaron controlar el tráfico de divisas generado, así como proteger y fomentar la producción nacional. Por su parte, la "Motion Picture Export Association of America Inc.» buscó la ayuda de su gobierno para imponer condiciones más favorables a la exportación de sus productos. Aqui se describen las negociaciones durante un periodo clave de las relaciones bilaterales que culminaría con la firma de los acuerdos de septiembre de 1953. Con semejante marco como trasfondo, se pretende identificar y describir la evolución de las diversas causas y factores que provocaron la incapacidad de las partes para alcanzar un acuerdo duradero que regulase la importación del producto cultural por excelencia del siglo XX.

Palabras Clave: Siglo XX. Relaciones España-Estados Unidos. Relaciones culturales. Comercio cinematográfico. MPEAA. Cine.

* Las fuentes primarias citadas en este trabajo corresponden a los fondos del Ministerio de Comercio depositados en el Archivo Central del Ministerio de Economía (ACME); los fondos del Archivo Renovado del Ministerio de Asuntos Exteriores (AMAE, R); los fondos de Comercio y Asuntos Exteriores del Archivo General de la Administración (AGA, MC y MAE); los fondos del IEME/Departamento Extranjero del Archivo Histórico del Banco de España (AHBE, IEME); los fondos del Instituto Nacional de Industria del Archivo de la Sociedad Española de participaciones Industriales (SEPI, INI); y los fondos de Jefatura del Estado del Archivo de Presidencia del Gobierno (APG, JE). Las abreviaturas utilizadas más frecuentemente son: MPPDA (Motion Picture Producers and Distributors of America); MPAA (Motion Picture Association of America); MPEAA (Motion Picture Export Association of America); SIMPP (Society of Independent Motion Picture Producers and Distributors); ECA (Economic Cooperation Administration); SEEC (Subsecretaría de Economía Exterior y Comercio); SRC (Subcomisión Reguladora de la Cinematografía); SOEC (Servicio de Ordenación Económica de la Cinematografía); DGCT (Dirección General de Cinematografía y Teatro); SNE (Sindicato Nacional del Espectáculo); IEME (Instituto Español de Moneda Extranjera); y DGCE (Dirección General de Cooperación Económica). 


\begin{abstract}
The negotiations on the import of American movies into Spain during Franco's dictatorship were left in constant limbo by theirs actors. On the one hand, Spanish authorities tried to control the foreign exchange generated by the imports, as well as to protect and encourage national motion pictures. On the other hand, the influential «Motion Picture Export Association of America Inc.» (MPEAA) sought to impose better conditions for its exports. This paper describes the talks during its first stage (1950-1955) coinciding with the intensification of the bilateral relations leading to the September 1953 Agreements. On so doing, it is sought to point out the main factors that motivated the incapacity of the actors to reach an agreement which would have brought stability and normalization into this economic and cultural transaction.
\end{abstract}

KEY WORDS: XX Century. Spanish-American Relations. Cultural Relations. Movie Trade. MPEAA. Cinema.

El papel que han jugado y juegan las transacciones cinematográficas en el conjunto de las relaciones hispano-norteamericanas está por determinar. La ininterrumpida presencia del cine norteamericano en España desde los años veinte del siglo pasado; su innegable rol como escaparate de pautas de conducta en la americanización española; o el hecho de que las negociaciones para su importación traspasasen el plano comercial para insertarse en el cultural y el diplomático; ofrecen sólo algunas de las razones por las que su estudio puede enriquecer el conocimiento de las relaciones bilaterales.

La bibliografía existente acerca de las negociaciones es escasa. Thomas $\mathrm{H}$. Guback se fijó en el periodo 1955-59. Su objetivo era ofrecer un ejemplo de las trabas, en forma de medidas proteccionistas, que los gobiernos europeos opusieron a la expansión de las películas norteamericanas tras la Segunda Guerra Mundial. La escasa documentación no puede sino confirmar lo superficial del acercamiento; algo que también se puede achacar al trabajo de K. Segrave. La investigación más completa hasta la fecha era sin duda la de Emeterio Díez Puertas, quien se interesó por el periodo 1951-52 sirviéndose de documentación fragmentaria. ${ }^{1}$

En este estudio hemos trabajado con material inédito que viene a complementar e incrementar la información disponible. El acceso a nuevos fondos hemerográficos y privados españoles, y sobre todo la consulta de los archivos norteamericanos, permitirán completar en un futuro los datos que se ofrecen a continuación.

1 Guback, T.: The International Film Industry: Western Europe and America since 1945, Indiana, Indiana University Press, 1969; DíEZ PuerTAS, E.: «El acuerdo cinematográfico hispanonorteamericano de 1952», Secuencias 4 (abril 1996), pp. 9-37; Segrave, K.: American Films Abroad: Hollywood's Domination of the World's Movie Screens from the 1890s to the Present, Jefferson, McFarland, 1997. Existe una edición en castellano de la obra de Guback: La Industria Internacional del cine (2 volúmenes), Madrid, Fundamentos, 1980. 


\section{LOS ACTORES DE LAS NEGOCIACIONES:}

\subsection{Washington y la MPEAA}

Aunque se ha matizado de distintas formas, la mayor parte de los estudios han identificado el inicio de la definitiva conquista del mercado internacional por Hollywood tras la conclusión de la Primera Guerra Mundial. Miembros relevantes de la industria y diversos investigadores han consensuado que la Web Pomerane Act (WPA) de 1918 y la colaboración activa de los Departamentos de Estado y Comercio con la industria cinematográfica bajo el lema «trade follows the film», espolearon a Hollywood hacia la conquista del mercado exterior. ${ }^{2}$ Con la intención de ofrecer un único interlocutor a los grupos de presión internos, la administración federal y los gobiernos extranjeros, las principales majors crearon en 1922 la Motion Picture Producers and Distributors of America (MPPDA). La conversión al sonido, la crisis del veintinueve y el posterior auge de políticas nacionalistas harían temer por el futuro de las exportaciones al viejo continente.

Esas sombras se esfumaron tras la Segunda Guerra Mundial. ${ }^{3}$ Las principales industrias europeas fueron nuevamente perjudicadas por la guerra cuando todavía no se habían recuperado del conflicto anterior. Además, los distintos gobiernos al oeste de Berlín carecían de autoridad, a la espera del maná norteamericano, para oponerse al desembarco económico-cultural que se diseñaba en Washington. En Hollywood, con un enorme stock tras años de conflicto, no podían sino frotarse las manos. En ese momento, concretamente en 1946, la

2 VALENTI, J.: Web Pomerane: The Great US Ally in the Battle for World Trade, First National Conference on Export Trading Companies, Washington DC, The US Chamber of Commerce, 1980; GUBACK, T.: «Film as International Business: The Role of American Multinationals», en G. KINDEM (ed.): The American Movie Industry, Carbondale and Edwardsville, Southern Illinois University Press (1982), pp. 336-350; ThOMPson, K.: Exporting Entertainment. America in the World Market, 1907-1934, Londres, BFI, 1985; Segrave, K.: op.cit; VASEY, R.: The World According to Hollywood, Exeter, Exeter U.P., 1997; o TRUMPBOUR, J.: Selling Hollywood to the World. US and European Struggles for Mastery of the Global Film Industry, 1920-1950, Cambridge y Nueva York, Cambridge University Press, 2002.

3 Guback fue el pionero en los estudios sobre el papel desempeñado por el Departamento de Estado en la expansión internacional de Hollywood tras la Segunda Guerra Mundial, concluyendo, con cierto seguimiento en medios académicos, sobre todo europeos, que la intervención del gobierno fue fundamental para el éxito de semejante expansión: GUBACK, T. H.: op. cit, 1969; MUSCIO, G.: Hollywood/Washington. L'industria cinematografica americana nella guerra fredda, Padova, Cooperativa libraria editrice degli studenti dell' Università di Padova, 1977; MILZA, P.: "Culture et relationes internationales», Relations Internationales 24 (invierno de 1980), pp. 361-379; SEGRAVE, K.: op.cit.; TRUMPBOUR, op.cit. Diversos autores sugerirían, sin embargo, que la conquista del mercado internacional se debió a la combinación de factores estructurales y/o fortuitos de los que la colaboración de su gobierno habría sido sólo uno más, y no el más importante: READ, W.: America's Mass Media Merchants, Baltimore, John Hopkins University Press, 1976; Tunstall, J.: The Media Are American, Londres, Constable, 1977; Pells, R.: Not Like Us. How Europeans Have Loved, Hated, and Transformed American Culture Since World War II, New York, Basic Books, 1997. 
MPPDA cambió su nombre por el de Motion Picture Association of America (MPAA), creando una filial dedicada en exclusiva a la distribución internacional de sus productos bajo el amparo de la WPA: la Motion Picture Export Association of America (MPEAA). Eric Johnston, cabeza visible del Partido Republicano, Presidente de la Cámara de Comercio de Estados Unidos, hombre excelentemente situado en Washington y futuro colaborador del presidente Eisenhower en política exterior, fue su primer presidente.

Los discretos resultados de la cooperación entre Hollywood y Washington durante el esfuerzo propagandístico de guerra, ${ }^{4}$ el eterno recelo de influyentes sectores sociopolíticos hacia Hollywood y la ley antimonopolio o Paramount Decree de 1946, no auguraban sin embargo una estrecha colaboración entre industria y administración en la nueva expansión. La ola anticomunista que inundó Hollywood y, sobre todo, las expectativas comerciales de la MPEAA y las nuevas necesidades culturales y propagandísticas de Washington modificaron el guión. ${ }^{5}$ Hollywood empuñó ahora la bandera de la propaganda para vencer la oposición interna a la colaboración entre industria y Departamento de Estado, argumentando con cierto éxito que sus películas eran el mejor escaparate de los valores de la democracia norteamericana en la lucha contra el comunismo. ${ }^{6} \mathrm{El}$ nuevo lema era «everything follows the film»; o para ser más exactos: «democracy follows the film».

\subsection{La administración franquista y la cinematografía.}

«Este negociado [...] elevará a V.I. una memoria explicativa de la situación en que se encuentra esta clase de industria [cinematográfica], exponiendo la multitud de irregularidades que encierra y las sugerencias correspondientes [...] evitándose o tratándose de aminorar en lo posible, los perjuicios cuantiosos que en la actualidad se están irrogando al Estado español» ${ }^{7}$.

4 Koppes, R. y Black, G. D.: Hollywood Goes to War: How Politics, Profits and Propaganda Shaped World War II Movies, Berkeley, University of California Press, 1990.

5 Existe cuantiosa bibliografía sobre la política cultural exterior de Estados Unidos en la Guerra Fría, de la que citaremos sólo algunos ejemplos representativos: THOMPSON, Ch. y LAVES, W. H.: Cultural Relations and US Foreign Policy, Bloomington, Indiana University Press, 1963; NINKOVICH, F.: The Diplomacy of Ideas, US Foreign Policy and Cultural Relations, 1938-1950, Nueva York, Cambridge University Press, 1981; Pells, R.: «Culture et politique étrangère: l'expèrience américaine en Europe depuis 1945», Relations Internationales et Stratégiques, 10 (1993), pp. 72-85; o KEYLOR, W. M.: «La propagande comme instrument de la puissance américaine dans les premières années de la guerre froide», Relations Internacionales, 94 (verano 1998), pp. 179-197.

6 La labor de defensa del valor propagandístico de las películas de Hollywood la asumió el propio Johnston: Johnston, E.: «Hollywood Still Best Ambassador of the United States Despite Some Contrary Opinions», Variety, 7 (enero de 1953).

7 Extracto de una Carta de Tomás Moral Alonso al Subsecretario de Comercio, Política Arancelaria y Moneda. Madrid, 7 de diciembre de 1940. AHBE, IEME-25. 
El régimen franquista acogió al cine en su regazo. La enorme debilidad de la industria local, agravada por los efectos de la guerra civil y la dependencia del mercado nacional de las importaciones, inspiraron a los gestores de la política comercial a poner bajo su control la economía cinematográfica. El Ministerio de Industria y Comercio hasta 1951 y, a partir de entonces, el Ministerio de Comercio fueron los entes gubernamentales encargados de la ordenación económica del sector. Con ese objetivo se creó en 1939 la Subcomisión Reguladora de la Cinematografía (SRC); y, en mayo de 1952, el Servicio de Ordenación Económica de la Cinematografía (SOEC). Entre el ministro y los órganos cinematográficos se situó la Subsecretaria de Economía Exterior y Comercio (SEEC) en 1947, lo que supuso la apropiación de la política cinematográfica por personal de Asuntos Exteriores, que copó la nueva subsecretaría en su disputa con Comercio por el control del comercio exterior ${ }^{8}$. Los diferentes subsecretarios nombrarían al frente de la SRC y el SOEC a colegas del cuerpo diplomático, pertenecientes a su vez al cuerpo de técnicos comerciales del estado. La dependencia del sector de las importaciones y el deseo del régimen de aumentar las exportaciones otorgó mayor protagonismo, si cabe, al Ministerio de Asuntos Exteriores, que a través de las distintas embajadas se encargaba de la labor diplomática en las relaciones cinematográficas.

Aunque nunca llegó a materializarse, la importancia que el régimen concedía a la cinematografía y el cariz de agujero económico que representaba ya a mediados de la de los años cuarenta, condujeron al régimen a buscar una fórmula de controlar e intervenir la industria directamente. La herramienta utilizada sería el Instituto Nacional de Industria, feudo de los más entusiastas intervencionistas del franquismo. Sin embargo, Cinematografía Española S. $A$. (CESA) nunca vio la luz. El porqué no es objeto de esta investigación, y aunque los motivos fueron variados, sin duda los de más peso fueron el coste económico de la operación y la oposición de buena parte de la administración y la industria, incluidas las filiales de las empresas norteamericanas. ${ }^{9}$

El Ministerio de Educación Nacional entre 1946 y 1951, y a continuación el Ministerio de Información y Turismo, se ocuparon de la gestión administrativa del cine a través de la Dirección General de Cinematografía y Teatro (DGCT). El Sindicato Nacional del Espectáculo (SNE), teórico representante de la industria cinematográfica, permaneció relegado a un segundo plano debido al temprano abandono de la senda nacionalsindicalista que había inspirado su creación. Cerrado el conducto sindical establecido para su comunicación, los tres grandes sectores de la industria, exhibición, distribución y producción, jugarían sus bazas en el terreno del amiguismo y el victimismo según el caso.

8 VIÑAS, A.: «La administración de la política económica exterior en España, 1936-79.» Cuadernos Económicos de ICE, 13 (1980), pp. 159-247.

9 Para el contenido del proyecto CESA, ver: SEPI, INI-2759. Existe un único estudio, una tanto limitado, sobre la documentación mencionada: QUENARDEL, A. L.: «L'intervention de l'INI dans l'industrie cinematographique espagnole 1946-52», Maîtrise d'histoire, Universidad de París IV, curso 1999-2000, sin publicar. 
En suma, la gestión de la cinematografía española se planteó desde sus inicios como una labor de equipo. La corrupción y las tensiones interdepartamentales que generó el sistema iban a demostrar el fracaso del modelo. Las negociaciones que nos disponemos a analizar representan sin duda un buen ejemplo de ello.

\section{ANTECEDENTES: HOLLYWOOD, ESPAÑA Y LA IMPORTACIÓN DE PELÍCULAS, 1939-1950.}

Entre 1922 y 1935 las filiales de las ocho majors se establecieron en España haciéndose con el control absoluto del mercado. ${ }^{10}$ La guerra civil supuso un punto y aparte. Para 1940 resultaba evidente que no se iba a restaurar el libre comercio en materia cinematográfica imperante durante los últimos años de la Segunda República. La sustitución de películas norteamericanas por alemanas e italianas, practicada en los primeros años de la Segunda Guerra Mundial, tampoco fomentó demasiadas simpatías al otro lado del charco. Por si fuera poco, el franquismo colocó en su punto de mira a Hollywood debido a las numerosas muestras de simpatía hacia el bando republicano, que habían emanado de la industria durante la guerra civil, y la importancia que los propagandistas del régimen otorgaban al cine para la proyección internacional del país. La calificación de un guión como antiespañol, ofensivo o difamatorio conllevaba la consiguiente reclamación ante los estudios productores y el Departamento de Estado. La frecuencia de desplazamientos de diplomáticos españoles a Los Angeles inspiró, incluso, la creación de un consulado en la ciudad a finales de los años cuarenta. Pese a determinados éxitos, el escaso volumen de películas importadas durante buena parte de la guerra limitó la efectividad de las reclamaciones.

A las tensiones políticas pronto se unieron las comerciales. El primer sistema de importación de películas del régimen franquista fue sancionado por Industria y Comercio en abril de $1941 .{ }^{11}$ Se estableció la obligatoriedad del doblaje al castellano de todas las películas visionadas en España, un canon de doblaje e importación para cada licencia y un régimen de importación en base a un intercambio puro de películas extranjeras por nacionales. En la teoría, los productores, una vez recibidos los permisos, los venderían a los distribuidores

10 En 1922 se estableció Universal Films Española S.A.; en 1924 Hispano Fox Films S.A.E.; en 1927 Paramount Films de España S.A.; en 1928 Metro Goldwyn Mayer Ibérica S.A.; en 1932 Warner BROS First National Films S.A.E.; en 1934 Radio Films S.A. (filial de RKO); y por último, en 1935, Columbia Films S.A. United Artists se estableció en España entre 1935 y 1936, aunque la fórmula empleada fue jurídicamente distinta, ya que Los Artistas Asociados S.A. figuró como su «distribuidor exclusivo».

11 Para un acercamiento a la legislación cinematográfica española durante el franquismo, VALlés COPEIRO DEl VILlar, A.: Historia de la política de fomento del cine español, Valencia, IVAC/La Filmoteca, 1992. 
para financiar sus películas. Los distribuidores, una vez conseguidos los permisos, podrían comprar las películas a los productores extranjeros, generalmente a través de acuerdos de compensación si la película era norteamericana. A las distribuidoras estadounidenses se les ofrecía la posibilidad de obtener permisos a cambio de la inversión en producciones nacionales, algo que raramente harían. A partir de mediados 1942, el giro bélico en favor de los aliados impulsó un aumento de las importaciones de films norteamericanos. Ello provocó la gestación de un mercado negro en torno al sistema de importación gracias al aumento de la demanda (en buena parte porque la legislación estaba diseñada para asumir un número decreciente de películas extranjeras), lo que obligó a las autoridades a plantear una política de protección.

Industria y Comercio instauró en mayo de 1943 la concesión directa de licencias de importación a los productores locales, en cantidad variable dependiendo de la calidad y precio de la producción. El objetivo era estimular una producción de calidad; el resultado, todo lo contrario, puesto que los especuladores advirtieron en seguida que el negocio residía en conseguir el mayor número de permisos de importación para especular con ellos. Éstos podían conseguirse «comprando» la calidad de la producción nacional a los funcionarios encargados de la calificación del guión o incrementando artificialmente su presupuesto («superproducciones» y star system a la española). Las filiales se veían atadas de pies y manos, puesto que si querían comercializar sus productos debían participar en el juego. Para colmo, la elevada cifra de películas importadas en los últimos años de guerra favoreció la multiplicación de pequeñas distribuidoras españolas que, amparadas por la especulación, llegaron a acaparar una importante parte del pastel a costa de las filiales ${ }^{12}$.

La corrupción también perjudicaba a la economía nacional; y más todavía a la calidad del cine español. Los permisos de importación debían ser cubiertos por las divisas que produjese la explotación en Estados Unidos de una película nacional, lo que implicaría la consiguiente licencia de exportación para el film español. La libre interpretación de la ley hizo estimar a los especuladores que, al adquirir el importador los derechos de la película norteamericana, éste quedaba liberado de las obligaciones legales a las que estaba sujeto el productor, quedando así exento de justificar el pago, que se hacía en dólares, y, por tanto, en dinero negro. Mientras, los beneficios que producía el film español, en el improbable caso de que se estrenase, quedaban en manos del exportador, privando así de cualquier beneficio al estado.

12 AMAE, R-1724/74 y ACME-5562. El caso más significativo de la participación de las filiales en el juego especulativo fue el de Hispano Fox. Esta trabajaba con una productora satélite, Emisora Films, que conseguía permisos de importación de la Fox, muchos de los cuales eran distribuidos por una distribuidora también satélite, Femi Films. Emisora Films llegó a producir 24 películas españolas, todas de escasa calidad, desde su fundación en 1943 hasta 1950. Esta cifra sólo fue superada por CIFESA, que en el mismo intervalo produjo 26 películas. 
Pese a las complicaciones comerciales y la antipatía del régimen, la mayor parte de las filiales, excepto las de Paramount y United Artists, sobrevivieron al periodo 1936-45 gracias, en buena parte, a la complicidad de los exhibidores y a la colaboración de su embajada, interesada en gestionar los fondos congelados a las filiales para cubrir gastos de propaganda, etc. Concluida la guerra, los ejecutivos de la MPPDA se plantearon obtener una flexibilización de las medidas intervencionistas. Para forzar la negociación la corporación amenazó al gobierno español con decretar un boicot de operaciones, escudándose en una reciente ley que limitaba el periodo de explotación de las películas importadas antes de 1939 a cinco años, lo que implicaba que muchas películas que apenas podían haber sido rentabilizadas por la penuria de posguerra tuviesen que volverse a casa. Representantes de ambas partes establecieron contactos a finales de 1945. Durante las conversaciones se trabajó en un proyecto de acuerdo de importación para el período comprendido entre el 25 de octubre de 1945 y el 31 de diciembre de 1946. Destacaba la cifra de 120 películas (80 a distribuir por las filiales) o la exigencia de que, tras su firma, CIFESA (principal productora y distribuidora nacional) desapareciese de la lista negra del Departamento de Estado. ${ }^{13} \mathrm{La}$ desfavorable coyuntura bilateral y la intensificación del intervencionismo económico del régimen evitaron el entendimiento.

El fracaso de las negociaciones, el embargo decretado por la ONU y la imposibilidad de la MPEAA de utilizar la presión diplomática ligada al Plan Marshall, que tan buenos resultados le había dado a la hora de vencer la resistencia de otros países, motivaron que la corporación optase por pasar a una fase de presión económica coordinada con su gobierno. La absoluta dependencia de la producción española del material virgen extranjero ofreció un blanco fácil. Sólo unos meses después de la ruptura de negociaciones, en marzo de 1946, quedó claro que Estados Unidos, principal productor mundial de película virgen, no iba a ofrecer ninguna facilidad a las importaciones españolas. España no cedió, aunque a costa de pagar un alto precio. La compra de material europeo y, cuando se disponía de dólares suficientes, la firma de costosos contratos con compañías norteamericanas, no sirvieron más que para parchear la situación. ${ }^{14}$ La corrupción que rodeaba a la industria cinematográfica agravó la situación.

En diciembre de 1946 Educación Nacional decretó la sustitución de los permisos de importación por los de doblaje. Los nuevos permisos serían conce-

13 AHBE, IEME-8 y ACME-5562. Segrave, K.: op. cit., p.164. La descripción de estas negociaciones realizada por Segrave resulta tan confusa como poco documentada.

14 AGA, MC-16740 y 16741; SEPI, INI-3513. GUBACK; y op. cit, 1985, p. 119. La principal fábrica española de película virgen durante los años cuarenta era la Sociedad Española de Productos Fotográficos VALCA, que a finales de la década producía unos 3 millones de metros (lo que no suponía más que una pequeña parte de las necesidades reales). Por si fuera poco, la factoría dependía de la importación del soporte celulósico. Los proyectos de sustitución de importaciones pasaron por varios proyectos, desde el los ligados al INI y CESA a mediados de los cuarenta; hasta la planta de Aranjuez Manufacturas Fotográficas Españolas, que no se inauguró hasta mayo de 1951. Esta empresa debía cubrir las necesidades de toda la industria española, algo que no consiguió ni de lejos. 
didos por el ministerio en función de una triple clasificación. La SRC juzgó la medida como una intromisión y un rechazo a la ley de obligatoriedad del doblaje. Para evitar un conflicto competencial se decidió hacer coexistir ambos permisos. El dinero recaudado iría al Fondo para el Fomento de la Cinematografía Nacional, gestionado por el SNE, que a su vez designaría a los productores destinatarios del crédito cinematográfico. La solución ejemplificaba la proliferación de licencias fruto de las disputas competenciales que caracterizaban la gestión del comercio exterior en la España autárquica.

Las medidas proteccionistas consiguieron reducir sensiblemente las importaciones y divisas empleadas, aunque no la crisis de la producción local y mucho menos la especulación. Las filiales, por lo general, acudieron para realizar sus transferencias a intermediarios extranjeros o españoles residentes en Estados Unidos, que obtenían en la transacción un cambio más favorable al oficial. ${ }^{15}$ Por otro lado, la oferta de licencias llegó a ser tan elevada que, citando a Díez Puertas, «los distribuidores norteamericanos podían conseguirlas más baratas, cobrar royalties más elevados e, incluso, exigir el pago en dólares». ${ }^{16}$ Las películas españolas seguían siendo mero instrumento de obtención de licencias, con la consiguiente repercusión en su calidad y explotación. Además, el abastecimiento de película virgen siguió bajo mínimos y, en febrero de 1950 , se llegó a temer por la producción del NO-DO, la niña bonita de la propaganda del régimen. Ante la actitud norteamericana y en la línea de la bilateralización promovida desde Industria y Comercio, la SRC cerró acuerdos de importación con Argentina (1948) y México (1950) para disminuir la dependencia del mercado de las películas norteamericanas. La corrupción, en este caso en forma de incumplimientos reiterados de los exhibidores de las cuotas de pantalla, disminuyó el efecto de esas medidas. Por su parte, en los países con los que se acababa de llegar a acuerdos se desconfiaba de que fuese a pasar mucho tiempo sin alcanzarse un arreglo entre España y la MPEAA. Eric Johnston había tenido una primera entrevista con Franco a finales de $1948 .{ }^{17}$

A pesar de sobrevivir a la corrupción y la legislación proteccionista, la situación fiscal de muchas de las filiales a la altura de 1950 era preocupante. La crisis de divisas potenciada por la ruptura del Protocolo Franco-Perón en 1949 habría acrecentado los problemas de transferencia de dólares. La MPEAA esperaba ansiosa el momento en que poder revertir la situación. Pese a las tensiones comerciales, las relaciones institucionales mejoraron para 1950. La histeria anticomunista que invadió Hollywood a finales de los años cuarenta convirtió al franquismo, de la noche a la mañana, en un inmejorable aliado para aquellos que

15 En determinadas ocasiones las filiales se dirigieron a las bolsas de Tánger, Lisboa o Suiza para realizar las transacciones a un cambio más favorables. ACME-5562.

16 Díez PuerTas, E., op. cit, p. 14.

17 AGA, MC-16746. Del contenido de la entrevista entre Johnston y Franco en 1948 no tenemos documentación, aunque si sabemos que esta fue de carácter privado, sin intervención de la embajada norteamericana. 
pretendían evitar sospechas respecto a sus afinidades políticas. Los estudios norteamericanos no dudaron en cortejar al régimen español. ${ }^{18}$ Sólo las disputas comerciales iban a evitar la proliferación de ese tipo de gestos en los años venideros.

Películas de largometraje importadas por España, 1939-195419:

\begin{tabular}{|c|c|c|}
\hline AÑO & NORTEAMERICANAS & TOTALES \\
\hline 1939 & 54 & 195 \\
\hline 1940 & 8 & 96 \\
\hline 1941 & 8 & 83 \\
\hline 1942 & 44 & 148 \\
\hline 1943 & 90 & 195 \\
\hline 1944 & 67 & 120 \\
\hline 1945 & 192 & 289 \\
\hline 1946 & 149 & 254 \\
\hline 1947 & 98 & 194 \\
\hline 1948 & 70 & 124 \\
\hline 1949 & 69 & 147 \\
\hline 1950 & 74 & 145 \\
\hline 1951 & 58 & 178 \\
\hline 1952 & 113 & 262 \\
\hline 1953 & 107 & 227 \\
\hline 1954 & 164 & 274 \\
\hline
\end{tabular}

\section{LAS NEGOCIACIONES ENTRE LA MPEAA Y EL GOBIERNO ESPAÑOL, 1950-1955.}

\subsection{De la primera toma de contacto al inicio de las conversaciones.}

Para 1950, la creciente bipolarización mundial invitaba a presagiar un acercamiento definitivo entre ambos países. Las compañías norteamericanas decidieron que era hora de reclamar un mejor trato. A mediados de abril, Eric Johnston comunicó sus intenciones a los diplomáticos españoles. En ese momento se debatía en el congreso y el senado norteamericano la concesión de un crédito a través del Export Import Bank a España. El embajador español, conocedor del peso político de la corporación, recomendó negociar ${ }^{20}$.

18 Como durante el viaje del general Gallarza, ministro del Aire, a California en marzo de 1950. AGA, MAE-8914.

19 Fuente: SOEC, Cuadro Estadístico de películas norteamericanas importadas entre 1939 y 1954 , Madrid, sin fecha. ACME-5562.

20 AMAE, R-3082/36 y AGA, MAE-12300. 
El 26 de abril Fernando Galainena, presidente de la SRC, recibió en su oficina al vicepresidente de la MPAA, John McCarthy, escudado por John Gilman, representante de la corporación en Europa y por Gerald G. Mayer, consejero comercial de la embajada. De entrada, McCarthy intentó hacer visible los perjuicios que el sistema de importación vigente estaba ocasionando a ambas partes. A continuación presentó un proyecto de convenio de importación para los próximos cinco años, tras los cuales debería volverse a un período de libre comercio. Su apuesta era fuerte: concesión directa de las licencias de importación a los distribuidores; instauración de un cupo anual de 106 películas, de las cuales 77 irían a parar a las filiales y el resto a distribuidoras locales; unificación de los permisos y cánones de importación y doblaje, así como del cartón de rodaje, en un solo pago de 250.000 pesetas por licencia (en esos momentos se estaban pagando más de medio millón por permiso de importación en el mercado negro, a lo que había que añadir el resto de cánones y tasas); garantía de satisfacción de las necesidades de película virgen de las filiales; y aval de permiso de transferencia de las filiales a sus casas matrices del equivalente en dólares al cambio oficial de las 250.000 pesetas desembolsadas por licencia, quedando los excedentes de la explotación bloqueados en España pero a libre disposición de las filiales para «gastos de su actividad».

Las demandas del delegado norteamericano implicaban la derogación del sistema de protección y sancionaban una clara discriminación positiva de las filiales ante las distribuidoras españolas. A cambio, la MPEAA se comprometía a la constitución de un fondo reintegrable sin interés alguno en el plazo de 10 años, con el objetivo de financiar la producción nacional a razón de 150.000 pesetas por licencia hasta un máximo de 50 millones al año; a prestar asesoramiento para la exportación de películas españolas al mercado norteamericano; y a la realización y proyección internacional de 10 documentales turísticos sobre España, lo que traducido en un incremento de visitantes, supondría un alivio para la balanza de pagos española. ${ }^{21}$

Aunque se rechazó la oferta, algo que probablemente preveía McCarthy por la ambición de sus propuestas, diversas voces en el seno de la SRC consideraron que era momento de mover ficha. La industria, por su parte, era consciente de que la corporación no se iba a quedar cruzada de brazos. Previendo la cercanía de nuevas conversaciones, desde el SNE se alzó la voz para reclamar un mayor protagonismo en el diseño del comercio exterior. El sindicato rescató una vieja aspiración: la aplicación literal de las medidas orgánicas estipuladas en octubre de 1940, que contemplaban el paulatino encuadramiento de la SRC bajo el organigrama del sindicato vertical; o bien, la creación de una Junta Asesora Cinematográfica presidida por el jefe del sindicato y con derecho a veto en materia de comercio exterior. Industria y Comercio hizo oídos sordos. ${ }^{22} \mathrm{La}$ pugna por el control de las competencias no había hecho más que empezar.

\footnotetext{
21 ACME-5562.

22 AGA, MC-16741.
} 
McCarthy regresó a Nueva York sin resultados concretos, aunque con el convencimiento de que un giro definitivo en las relaciones bilaterales ofrecería el contexto adecuado desde el cual forzar un cambio. El levantamiento de las sanciones de la ONU a finales de año y la consiguiente normalización de las relaciones bilaterales ofrecieron la oportunidad esperada.

Stanton Griffis fue nombrado embajador de Estados Unidos en España el primero de febrero de 1951. El puesto permanecía vacante desde que Norman Armour concluyó su misión a finales de 1945. El régimen presentó el acto como un triunfo internacional; la MPEAA podía sentir algo similar. Griffis era un hombre de la industria del cine. Desde los años treinta ocupaba un sillón en el Consejo Ejecutivo de Paramount Pictures Inc. Durante la Segunda Guerra Mundial siguió ligado a la industria cinematográfica desde las agencias de inteligencia. En octubre de 1942 pasó a formar parte de la Office of Strategic Services, convirtiéndose en su agente para Suecia, Finlandia, Portugal y España. La $\mathrm{Pa}$ ramount, que había abandonado varios de esos países (entre ellos España), puso a disposición de la agencia sus fondos en el extranjero. De hecho, Griffis se alojó en la oficina que la compañía tenía en Madrid durante una misión en la capital entre enero y febrero de 1943. Ese mismo año realizó labores de mediación entre la MPPDA y el gobierno español, concretamente en operaciones de compensación para el pago de importaciones. En septiembre de 1943 ingresó en el Office of War Information, donde desempeñó la presidencia del consejo del Motion Pictures Department hasta la primavera de 1944. Su labor consistió en coordinar las relaciones entre Hollywood y Washington, así como en gestionar la información cinematográfica obtenida de las distintas legaciones internacionales. ${ }^{23}$ Para reforzar su currículo como hombre fuerte de Hollywood, durante sus embajadas en Polonia, Egipto y Argentina participó activamente en negociaciones cinematográficas de carácter bilateral (como lo eran siempre que intervenía la MPEAA).

Desde su nuevo puesto, Griffis no tardó en mostrar un especial interés en los asuntos cinematográficos. Johnston, apoyado por la embajada, vino a España para entrevistarse nuevamente con Franco. En marzo, el embajador advirtió a las autoridades que en caso de no producirse un cambio de actitud respecto a las importaciones, la MPEAA decretaría un boicot comercial con el respaldo de su gobierno. Países como Argentina, Dinamarca, Australia o Gran Bretaña habían accedido recientemente a las pretensiones de la corporación tras meses de boicot. Además, contemporáneamente la corporación estaba en pleno proceso negociador con Italia y Francia, por lo que no podía dar señas de debilidad alguna, especialmente en un mercado de tipo medio como el español. Aparte de los daños económicos que acarreaba la ausencia de sus películas en las salas de los distintos países (pérdida de empleo en la exhibición, descapitalización de fondos de fomento ligados a las importaciones, etc.), la corporación desencade-

23 GriffIS, S.: Lying in State, Garden City, Double Day, 1955, p. 102. 
naba toda su capacidad propagandística contra el país de turno, acusándole, por ejemplo, de contravenir el libre comercio propio del «mundo libre». ${ }^{24} \mathrm{La}$ amenaza se cumplió en mayo de 1951. La producción española entró en crisis y la reacción de la administración fue inmediata. Las negociaciones comenzaron ese mismo mes. La iniciativa estaba del lado norteamericano.

La delegación española que inauguró las conversaciones estuvo encabezada por el Subsecretario de Economía Exterior y Comercio, Tomás Suñer Ferrer y completada por su jefe de gabinete, Javier Elorza y Fernando Galainena. Suñer no era precisamente un «don nadie». Técnico comercial y diplomático había sido elegido para el cargo en febrero de 1947. Para entonces tenía a sus espaldas una larga experiencia como representante diplomático en diversos países, sobre todo latinoamericanos, así como en la negociación de importantes acuerdos comerciales como el Protocolo Franco-Perón. La medida más conocida que promovió desde la SEEC fue el caótico sistema de pagos múltiples. Javier Elorza, también diplomático, había participado como representante de la Dirección General de Política Arancelaria en las negociaciones comerciales con Estados Unidos durante la Segunda Guerra Mundial y, justo antes de su nombramiento, había ocupado la agregaduría comercial de la embajada española en Washington. El currículo de los delegados españoles evidenciaba la importancia, al menos de cara a la galería, que el régimen otorgaba a las negociaciones. También resultaba cuanto menos llamativa la ausencia de personal de Educación Nacional.

Los contactos comenzaron la mañana del 15 de mayo de 1951 en la embajada. McCarthy compareció respaldado por Griffis y el Encargado de Negocios, Daniel M. Braddock. En representación española acudieron Suñer y Elorza. En el transcurso de la reunión, Griffis trasmitió el deseo de su gobierno de que se modificase el sistema de importación. Al día siguiente, McCarthy expuso las reclamaciones de la corporación en forma de proyecto de acuerdo para los próximos tres años. Buena parte de las demandas giraban en torno a las reclamaciones transmitidas el año anterior: concesión directa de las licencias a los distribuidores; unificación de los permisos y cánones en una licencia de importación de cuantía decreciente del primer (600.000 pesetas) al tercer año (400.000 pesetas); cupo de 110 licencias para el primer año (creciente en 10 licencias por temporada), repartidas a razón de 96 para sus asociadas (incluida la ausente Paramount) y 14 para las distribuidoras españolas (las filiales se comprometían a absorber los permisos de importación concedidos en el último período de vigencia del sistema actual); y garantía de suministro de material virgen a las filiales. Donde sí se apreciaban cambios sustanciales era en las transferencias. La MPEAA reclamaba un sistema de explotación por «distribución», reservándose un máximo de un treinta por ciento para gastos de soste-

24 Como en el caso británico en 1948: SwANN, «Hollywood in Britain: The Postwar Embargo on Exporting Feature Films to Britain", en Austin, B. A. (ed) Current Research in Film: Audiences, Economics and Law, $\mathrm{n}^{\circ}$ 3, Norwood, Ablex Publishing, (1987), pp. 105-120. 
nimiento de las filiales. El resto sería transferido a Estados Unidos por medio de una cuenta bloqueada, en la que el Instituto Español de Moneda Extrajera (IEME) iría depositando dólares en función de su disponibilidad. Se reclamaba además libertad absoluta para utilizar los fondos bloqueados para gastos de las compañías en España; y derecho a la retención de las divisas obtenidas por películas americanas rodadas o sincronizadas en España sin cargo alguno. También era novedosa la propuesta de derogación de la censura posterior al doblaje, con el objetivo de ahorrar gastos de laboratorio; y sobre todo, el final del monopolio informativo de NO-DO. Este punto era el único que respondía a intereses propios del gobierno norteamericano, puesto que los noticiarios de las majors se encontraban en franco declive en esa época. Como contraprestaciones, la MPEAA ofrecía colaboración para la adquisición de divisas por España a través de la venta de determinados productos en cines norteamericanos; el estudio de una fórmula de crédito de hasta 100.000 dólares anuales para la adquisición de equipos técnicos para la industria española; y el asesoramiento de RKO, Universal y Paramount en la distribución de películas en Estados Unidos. ${ }^{25}$ La aceptación de semejantes proposiciones era difícilmente asumible para los negociadores españoles, menos aún en el plazo propuesto y a cambio de tan escasas contraprestaciones. De entrada, los negociadores españoles se negaron a discutir sobre la censura y el monopolio informativo del NO-DO. Los norteamericanos asintieron y ninguno de los dos puntos volvió a aparecer entre las propuestas norteamericanas, lo que no hacía sino recalcar las prioridades de la delegación norteamericana. El 26 de mayo McCarthy dio a Suñer un plazo de 30 días para recibir una contraoferta.

Los primeros estudios de la SRC dejaban entrever cierta sintonía con la propuesta norteamericana. En lo referente al cupo se manejaban cifras similares. La unificación del canon de importación y doblaje se aceptaba, aunque se esperaba conseguir un precio más elevado por película. La coincidencia en este asunto era comprensible ante el enfrentamiento entre Industria y Comercio y Educación Nacional por los permisos de doblaje. El sistema de explotación por distribución se consideraba aceptable siempre que no existiese un compromiso explícito a establecer envíos regulares. Donde existía un claro desacuerdo era en la fecha de entrada en vigor del acuerdo, que retrasaban como pronto al primero de octubre, y en el período de vigencia, nunca superior a un año. ${ }^{26}$

Pese a que el plazo pasó sin respuesta, la MPEAA permaneció a la espera ante el debate interno en la delegación española. Los sucesivos proyectos, elaborados en el seno de la SRC a finales de junio y principios de julio, derivaron hacia tesis lejanas a las demandas norteamericanas. Aceptado el modelo de transferencias, los delegados españoles centraron sus esfuerzos en mantener el sistema de importación ligado a la producción, aunque más racionalizado. Al

25 ACME-5562 y AGA, MC-16741.
26 ACME-5562.

Hispania, 2006, vol. LXVI, nº. 222, 277-318, enero-abril, ISSN: 0018-2141 
mismo tiempo se pretendía contener el número de importaciones arguyendo criterios de orden monetario (divisas) y de regulación del mercado (competencia a las películas españolas). Los cálculos de la SRC establecían el cupo de importaciones aceptable —sobre un cálculo de 40 producciones nacionales — en torno a 210 películas extranjeras al año, de las cuales entre 85 y 90 serían norteamericanas. Respecto al reparto del cupo, se mantuvo más o menos estable en una proporción de «2 a 1» a favor de las compañías norteamericanas. Los precios barajados para las licencias de importación y doblaje oscilaron entre 600.000 y 700.000 pesetas por película. El período de vigencia debía de ser por un año, a lo sumo dos. ${ }^{27}$

El 4 de julio el ministro de Industria y Comercio recibió un extenso dossier de Suñer sobre la situación de la cinematografía nacional. En su parte final adjuntaba una contrapropuesta al proyecto de McCarthy. El informe respondía a un encargo del año anterior. Suñer lo comenzaba excusándose por el retraso, dilación que atribuía al inicio de las negociaciones y a la consiguiente necesidad de evitar la adopción de medidas que "quizás pudiera servirnos más tarde como elemento de negociación». El Subsecretario defendía «la necesidad de una reforma total» y en el menor plazo del marco legal en que se desarrollaban las actividades y transacciones cinematográficas. A lo largo de las páginas iba enumerando los principales problemas de cada sector para detenerse en la producción, y más concretamente, en el funcionamiento del sistema de importación y fomento. Suñer afirmaba que "desde 1941, ni una sola película americana de las que se han importado en España ha sido pagada por el conducto legal». También incidía en los problemas generados por ello: la creación de una considerable «bolsa negra» de divisas; la imposibilidad de organizar la exportación de las películas españolas; la corrupción y ruina de la producción; y el peligro de desaparición de las distribuidoras nacionales. A la hora de buscar culpables el subsecretario apuntaba sin miramientos a los «privilegiados» empresarios de la producción. A pesar de todo, aconsejaba que no se suprimiese el marco vigente «para que no parezca que se hace bajo la presión de intereses extranjeros». Su contraoferta seguía la pauta de los últimos estudios de la SRC. ${ }^{28}$

Entretanto, el ambiente cinematográfico continuaba en ebullición por la incógnita que generaban las negociaciones y los problemas de abastecimiento de las salas acarreados por el boicot. La exhibición reclamaba la llegada de material norteamericano, por lo que apoyaba la firma de un acuerdo tan pronto como fuera posible. Los distribuidores simplemente requerían un porcentaje aceptable de las importaciones. En la producción todo era más complicado. El 6 de julio los subgrupos de Actores Cinematográficos, Técnicos, Figurantes y el personal administrativo y obrero dirigieron una carta a Suñer. Los firmantes reclamaban la explotación obligatoria en versión original del material extranje-

27 ACME- 5562.

28 ACME-5562. 
ro. Conscientes de la inviabilidad de su propuesta, planteaban como alternativa que la importación de películas dobladas se limitase a un número reducido por temporada y bajo "cánones especiales y permisos de doblaje, debidamente vinculados a las películas españolas». La sombra de los empresarios planeaba detrás. El día 9 fueron los vocales de los estudios y de la producción los que propusieron, esta vez a Galainena, el mantenimiento del sistema anterior. ${ }^{29}$

\subsection{Del preacuerdo de París al primer convenio cinematográfico bi- lateral.}

La contrapropuesta definitiva fue consensuada a finales de junio por Suñer, Elorza, Galainena, Suevos (SNE) y Gabriel García Espina (DGCT). El texto, presentado el 11 de julio, contemplaba un convenio por un año prorrogable a otro; el mantenimiento del sistema de entrega de los permisos a los productores, quienes los cederían a los distribuidores a través de la SRC; un canon de 650.000 pesetas (dividido como exigencia de la DGCT en 630.000 para el canon de importación y 20.000 para el de doblaje); la concesión de 85 licencias anuales; el reparto equitativo del cupo entre las filiales y las distribuidoras españolas; y la aceptación a que las transferencias se hiciesen conforme a la propuesta norteamericana, especificando que la cuenta donde los fondos debían ser bloqueados se abriese en el IEME. El día 13, la MPEAA comunicó su rechazo y el mantenimiento de todas sus pretensiones. Tras una veloz ronda de consultas Suñer ofreció aumentar el porcentaje de películas destinadas a las filiales hasta un cincuenta y cinco o un sesenta por ciento. La esperada negativa fue comunicada por McCarthy el día 25, aduciendo como principal causa el reducido número de licencias. ${ }^{30}$ Mientras la MPEAA se ofrecía a reanudar las conversaciones, Griffis aumentó la presión metiendo el dedo en la llaga de las relaciones bilaterales:

«En el curso de la últimas semanas el Consejero de la Embajada de Estados Unidos Sr. Braddock y personalmente el Embajador Griffis han insistido en forma apremiante para que se modificara el vigente sistema de importación de películas norteamericanas en España. Tanto el Sr. Embajador como su Consejero han atribuido a este asunto importancia excepcional manifestando su impresión de que el desarrollo que tuviera podría influir en otros aspectos de las relaciones económicas de ambos países» 31 .

29 AGA, MC-16746 y ACME-5562.

30 ACME-5562.

31 Comentario de Suñer al cable enviado por McCarthy a Tomás Suñer, Madrid, 25 de julio de 1951. AGA, MC-16741. 
El julio, el Ministerio de Industria y Comercio fue dividido. El nuevo ministro de Comercio, Manuel Arburúa, estrenó una política basada en la expansión del intercambio, la normalización del abastecimiento interior y la mejora de la política arancelaria. El nombramiento de Arburúa ha sido interpretado como un guiño del régimen hacia Estados Unidos (había ocupado la vicepresidencia de la cámara de comercio norteamericana). En las negociaciones, este guiño se tradujo en un cambio de personal bastante significativo: la sustitución de Suñer por Jaime Alba, hermano del director general de MGM Ibérica S.A., César Alba. La situación de bloqueo en las negociaciones con la MPEAA debió pesar en la decisión del ministro. Alba, diplomático especializado en la negociación de acuerdos comerciales, pronto demostraría una gran sintonía con los norteamericanos. Por su parte, la DGCT, ahora dependiente de Información y Turismo y dirigida por el combativo José María García Escudero, inauguraba una fase de mayor protagonismo, quizás como contrapeso al nombramiento de Alba. Pese a todo, las tensiones en el lado español no desaparecieron. El 6 de agosto, Galainena denunció a Alba la actitud de las productoras norteamericanas al incrementar los precios exigidos a las distribuidoras españolas por la cesión de sus películas (en represalia a la contrapropuesta española). El tono utilizado dejaba entrever sus sospechas hacia las relaciones de su superior con las filiales. Galainena sería cesado en agosto. ${ }^{32}$

Poco a poco las negociaciones se centraron en dos puntos: el contingente anual de licencias y su reparto. Las conversaciones se desplazaron a San Sebastián, centro vacacional por excelencia de los altos cargos del régimen. En representación española acudieron Suñer, ahora ministro plenipotenciario para las negociaciones; y Elorza, ahora agregado de Economía Exterior. Llamaba la atención la ausencia de Alba, Galienena y García Escudero. McCarthy acudió junto a Allport. Las discusiones tomaron como base la contrapropuesta del 11 de julio. Excepto en el período de duración, que pareció establecerse en un año con opción de prórroga por otro más, las diferencias eran todavía significativas. Respecto al cupo, los norteamericanos exigían 110 licencias a razón de 600.000 pesetas por cada una; por las 85 o 90 y 650.000 pesetas ofrecidas por los españoles. Suñer veía posible un entendimiento. En la distribución de los cupos los españoles se mantenían en la propuesta de un reparto equitativo, llegando a lo sumo a un cincuenta y cinco por ciento para las filiales; los norteamericanos pedían más del setenta por ciento. Suñer consideraba que no se debía ofrecer más de un sesenta. Los norteamericanos mantenían su exigencia de la entrega directa de las licencias al distribuidor, aunque, matiz importante, ya no hablaban de derogación del régimen vigente; los españoles repetían la posición «intermedia» del 11 de julio. Suñer creía que, como se venía constatando en los últimos encuentros, este punto acabaría siendo aceptado siempre que se aumentase el cupo, dado que el principal propósito de la MPEAA era acabar con la fluctuación del precio de las licencias. ${ }^{33}$

\footnotetext{
32 ACME-5562.

33 ACME-5562.
} 
El 13 de agosto las tensiones competenciales irrumpieron de lleno en las negociaciones. Sucesivamente, Alba y García Escudero telefonearon a Suñer para reprocharle que no debía excluir de las negociaciones a la DGCT y, horas más tarde, que en común acuerdo habían determinado la inmediata suspensión de las conversaciones entretanto Información y Turismo no «estudiase la situación». Suñer, enojado, acató las órdenes, aunque advirtió a sus superiores que los temas en discusión competían en exclusiva a Comercio, así como del malestar que iba a causar la decisión al embajador. ${ }^{34}$ El día siguiente las negociaciones quedaron suspendidas y Suñer definitivamente apartado. Su cese vino acompañado del de Galainena, relevado por Elorza. Podía intuirse que, a pesar de las diferencias entre Alba y García Escudero, ambos habían pactado hacerse con el timón en el último momento, bien para colgase las medallas de un acuerdo, bien porque entendían que la dupla Suñer-Galainena representaba en sí misma un obstáculo. Los acontecimientos inmediatos parecieron confirmar ambas hipótesis.

El 29 de agosto, Elorza, García Escudero y McCarthy alcanzaron un principio de acuerdo en los puntos en discordia. A cambio de la cesión española en la cifra del cupo, la MPEAA ofreció ayuda económica, de forma imprecisa, a la industria española. En el principio de acuerdo destacaban la cifra de 100 películas a importar entre el primero de octubre de 1951 y el 30 de septiembre de 1952 (14 meses); un reparto del cupo «3 a 2» a favor de las filiales; una cifra a establecer en concepto de canon de importación y doblaje; un permiso de doblaje, como quería la DGCT; y el compromiso de la corporación de gestionar ante la European Cooperation Administration (ECA) un crédito de 350.000 dólares para modernizar los estudios españoles. La promesa de mediación respecto a un crédito suponía una victoria moral para la delegación española, ya que se trataba de la primera mención en un documento hispano-norteamericano de una posible donación de la ECA. ${ }^{35}$

Las conversaciones se reanudaron a mediados de septiembre. La sede fue la oficina central de la MPEAA en Europa, sita en París. Tras varios días de reuniones las partes llegaron a un proyecto de acuerdo de 15 puntos sobre el del

34 Según Díez Puertas, Escudero acudió a San Sebastián el día 13 con una serie de propuestas bajo el brazo. DíEz PUERTAS op. cit, pp. 23-24. En las mismas páginas culpa a Elorza, que al parecer tendría una mala relación con García Escudero, de no haber avisado a éste. La información que poseemos parece apuntar que, en todo caso, fue Suñer quien prescindió de Información y Turismo; aunque, según el exsubsecretario, el subsecretario de ese ministerio, Cerviá Cabreras, era plenamente conocedor de la reunión. La documentación consultada no apunta la presencia física de García Escudero en las negociaciones de San Sebastián.

35 AMAE-R 3082, 36. Un informe a título personal redactado por Alfonso Acebal y Monfort para Javier Elorza redactado a mediados de 1951, apuntaba que «en todos los estudios de Madrid sólo existe una grúa, una truca y un equipo de transparencias para más de treinta películas anuales»: Alfonso Acebal y Monfort, Proyecto de Normas de protección a la industria cinematográfica española, Madrid, 13 de julio de 1951. ACME-5563. 
día 29. Las únicas novedades fueron la duración del acuerdo, ahora del primero de noviembre de 1951 al 31 de octubre de 1952; y el precio de las licencias, fijado en 638.000 pesetas. La ejecución quedaba pendiente de la aprobación o reservas de las partes. Respondiendo a las exigencias españolas, McCarthy reiteró por escrito a Alba y Gabriel Arias Salgado (ministro de Información y Turismo) su compromiso a trabajar en la consecución de un crédito ante la ECA para la cinematografía española. ${ }^{36}$

Al volver a Estados Unidos McCarthy se encontró con una desagradable sorpresa. Los miembros de la Society of Independent Motion Picture Producers (SIMPP), además de United Artists, Monogram y Republic (asociadas de la MPEAA sin filial en España) se negaron a aceptar lo acordado. Las quejas llegaron al Departamento de Estado, desde donde se recordó a Griffis que la intervención de la embajada se justificaba en defensa de todos los intereses en juego. Los demandantes reclamaban un cupo anual que les asegurase un determinado volumen del negocio; es decir, la garantía de que un mínimo de las películas importadas saliesen de sus estudios. El temor de los independientes consistía en que las distribuidoras españolas destinasen sus 40 permisos a películas de las majors. Monogram, Republic y United Artists reivindicaban por su parte un número de licencias similar al de las casas con filiales, que se habían asegurado entre 8 y 10 cada una. Además, Republic y United Artists exigían el derecho a designar un distribuidor exclusivo, como venía haciendo la segunda a través de $C B$ Films desde 1946. El conjunto de las reclamaciones vulneraba el espíritu de la cláusula IV del preacuerdo de París, que garantizaba la libertad de elección de las distribuidoras españolas. Una nueva negociación parecía inevitable. La corporación dio los primeros pasos: levantó el boicot comercial como muestra de buena voluntad (y ante el inicio de la temporada alta cinematográfica en septiembre) y nombró a Timothy Healey, antiguo colaborador de Griffis en Egipto, como negociador para España. ${ }^{37}$

El 26 de septiembre Gregorio Marañón Moya, abogado de la corporación, hombre bien relacionado con las jerarquías del régimen y ligado a numerosos intereses comerciales norteamericanos, comunicó el contratiempo. Aprovechó para trasladar a Alba una invitación para discutir en Nueva York tanto esas dificultades como los pormenores del acuerdo y los medios de facilitar el paso del viejo sistema al nuevo. Healey y Griffis recalcaron el interés de su gobierno en que la delegación española se trasladase a Nueva York. La respuesta española se hizo esperar. Finalmente, contra la voluntad de Alba, el ministro exigió que las negociaciones tuviesen lugar en Madrid, con la excusa de evitar suspicacias entre la industria local. ${ }^{38}$

García Escudero deseaba ampliar sus competencias a la ordenación económica para poder desarrollar una auténtica política de fomento. Desde Industria

\footnotetext{
36 AMAE, R-3082/36 y ACME-5562.

ACME-5562.

38 ACME-5563.
} 
y Comercio esas aspiraciones se observaban con recelo. Según Alba, García Escudero pretendía la separación de los cánones de importación y doblaje establecidos en el preacuerdo de París, quedando el segundo en manos de Información y Turismo para aumentar el peso de la DGCT en futuras negociaciones. En plena polémica, Arburúa intervino a favor de Alba y acabó con las aspiraciones de García Escudero, quien no encontró el respaldo de sus superiores y quedó desplazado de las conversaciones. ${ }^{39}$ Los intereses económicos y diplomáticos se imponían claramente a los del fomento del cine español.

El retraso en la ratificación del preacuerdo comenzó a generar tensiones en ambas delegaciones. A finales de noviembre, la Fox (la filial con mayor margen de negocio en España) amenazó con romper el preacuerdo, ya que entendía que el cupo asignado por empresa era escaso. Detrás de esa actitud se encontraba su deseo de obtener la concesión de un cupo extraordinario de 6 permisos bajo el sistema vigente. Por parte española, al creciente enfrentamiento entre los dos ministerios implicados se unieron nuevamente las reclamaciones del SNE. En semejante tesitura, Elorza propuso la ejecución unilateral y sin previo aviso de ciertas medidas (no concretadas) en torno a la protección y la importación. Según él mismo, algunas filiales estaban dispuestas a aceptarlas, aunque sólo citaba a la MGM Ibérica de César Alba. ${ }^{40}$

Mientras tanto, Healey propuso separar del cupo reservado a las distribuidoras españolas un número a importar de las empresas en rebeldía. Elorza se negó, ateniéndose a lo firmado en París y aludiendo a la libertad de mercado. El 17 de noviembre se reunieron representantes de la embajada, Healey, Elorza y Manuel Cerviá Cabreras, Subsecretario de Información y Turismo. En el transcurso de las conversaciones, el norteamericano mostró la disposición de la MPEAA a ratificar el preacuerdo en el caso de obtener una solución satisfactoria a dos reclamaciones. La primera escondía el deseo de las majors (especialmente de Hispano Fox) de obtener los permisos de importación que se habían paralizado por el desarrollo de las negociaciones. En concreto reclamaban que el organismo competente clasificase antes de fin de año el mayor número posible de producciones españolas, con el fin de conceder las licencias de importación correspondientes bajo el régimen todavía vigente. Al mismo tiempo, solicitaban que en todos aquellos casos en que las filiales hubieran satisfecho en parte o en su totalidad el pago a la casa matriz antes del 31 de diciembre, se concediese a los productores españoles un plazo de doce meses para obtener los permisos sin que fuesen imputados en el cupo acordado para la temporada 1952-1953. La delegación española asumió ese compromiso. La segunda reclamación consistía en que 20 de las 40 licencias concedidas a las distribuidoras españolas se destinasen a películas de Monogram, Republic y United Artists. Elorza se negó. ${ }^{41}$

\footnotetext{
39 ACME-5563.

40 ACME-5562 y 5563.

41 ACME-5562 y 5563.
} 
El 7 de enero de 1952 Healey escenificó un cuádruple guiño a la delegación española. En primer lugar, ofreció la disposición de Eastman Kodak a facilitar millón y medio de metros de película virgen negativa a un precio ventajoso. También comunicaba la resolución de las filiales de abastecerse de película positiva por su cuenta y riesgo, aliviando así la situación del stock español. En tercer lugar y más importante, comunicaba la aceleración de las gestiones en torno al crédito de 350.000 dólares ante la Mutual Security Agency (MSA), heredera de la ECA. Por último, garantizaba el interés de la corporación por comercializar las mejores películas españolas en Estados Unidos. Las propuestas eran lo suficientemente apetitosas como para que Alba «vendiese» a su superior las contrapartidas obtenidas a cambio de la cesión en lo referente a la cláusula IV; y lo suficientemente vagas como para entenderlas como una simple excusa con que acallar a la industria e Información y Turismo. Bien por presiones superiores que exigían la firma de un convenio, bien porque se entendía aceptable lo acordado - lo que es discutible teniendo en cuenta el posterior desarrollo del acuerdo- Arburúa aceptó. Tras desechar la utilización de cupos extra, los delegados españoles elaboraron una propuesta definitiva aceptando las 20 licencias, aunque con ciertas matizaciones que se plasmarían en el acuerdo. Los norteamericanos asintieron. ${ }^{42}$

El 22 de enero Alba, Cerviá, Griffis y Healey rubricaron en Madrid el Primer convenio cinematográfico hispano-norteamericano. Llama la atención el nombre del tratado, puesto que este había sido negociado entre dos corporaciones privadas, la MPEAA y la SIMPP; y un estado. Los motivos podían ser dos: que la intervención de la embajada en las negociaciones se hizo en nombre de todos los intereses cinematográficos norteamericanos y, por tanto, así debía quedar plasmada en la letra del acuerdo; o que fuera una exigencia del gobierno español para su posterior utilización propagandística.

El texto definitivo no contemplaba modificación alguna respecto al estipulado en París, exceptuando el período de vigencia, ahora del primero de marzo de 1952 al 28 de febrero de 1953, así como la inclusión de un apéndice incluyendo tres párrafos a la cláusula de la discordia. El contenido final de la cláusula IV dispuso que de las 40 películas a importar por las casas españolas, 5 deberían ser adquiridas a los asociados de la SIMPP y 15 a Republic, Monogram y United Artists. Los cupos podrían ser intercambiados entre esas empresas durante los dos meses siguientes a los seis primeros de convenio. Transcurridos los primeros ocho meses de vigencia del acuerdo, la parte o totalidad de esas 20 películas que no hubiesen sido adquiridas, podría ser utilizada por las casas españolas que a ello tuviesen derecho, con entera libertad para importar películas de cualquier firma. La vaguedad de cláusulas importantes como las que regulaban el nuevo sistema de importación y el sistema de transferencias resultaban cuanto menos llamativas. Teniendo en cuenta el uso interesado que se

\footnotetext{
42 ACME-5563.
} 
realizó posteriormente, parece lícito sospechar que tal indefinición fue un objetivo en sí mismo para ambas delegaciones.

El régimen no quiso dejar pasar la oportunidad de hacer público el primer acuerdo comercial alcanzado entre Estados Unidos y la España franquista. El día 27, en el Palacio de la Santa Cruz, con la presencia de Griffis, los ministros de Asuntos Exteriores y Comercio y la prensa, se escenificó nuevamente la firma. Desde la perspectiva del régimen, el evento constituía una buena antesala para las negociaciones bilaterales que concluirían en los convenios de septiembre de $1953 .{ }^{43} \mathrm{El} 28$ de enero, pocos días después de la consecución del acuerdo, Griffis renunció a su cargo de embajador. Su misión estaba cumplida: España había modificado su sistema de importación. ${ }^{44}$ Sin embargo, los industriales norteamericanos pronto se darían cuenta de que una cosa era conseguir cerrar un acuerdo con la administración franquista y, otra muy distinta, que se ejecutase.

\subsection{Acuerdo «fantasma».}

Las reacciones al convenio se sucedieron en España. La producción puso el grito en el cielo ante lo que entendía una traición a los intereses de la industria nacional. Se reclamó la derogación del convenio y el reforzamiento de las medidas de protección ligadas a la importación, y es que los empresarios especuladores, que eran mayoría, veían peligrar su negocio.

Alba, una vez firmado el acuerdo que parecía haber buscado con tanto empeño, abandonó su puesto. Su sustituto, el también diplomático Jaime Argüelles Armada, ocuparía la subsecretaría hasta agosto de 1955.45 Al contrario que sus predecesores, Argüelles cedió la dirección de las negociaciones a sus subordinados. Elorza fue el elegido, primero desde la SRC y, posteriormente, como primer jefe del SOEC. Los movimientos de personal también afectaron a Información y Turismo. García Escudero, arrinconado en el tramo final de las

43 TacCOnI, S.: «Acuerdos y convenios de España con los EEUU», Revista de Economía, 8 (1955), pp. 37-38. La felicitación del Departamento de Estado norteamericano no tardó en llegar: nota confidencial de la Embajada de Estados Unidos al MAE, Madrid, 8 de febrero de 1952. AMAE, R-3082/36.

44 Stanton Griffis se retiró de la vida pública tras su misión en España, aunque mantuvo varios años su puesto en la Paramount. Justificó su decisión por motivos de salud y por el conflicto de intereses que se le creaba ante el conflicto judicial que sostenían Paramount y el gobierno federal por el Paramount Decree (aunque había comenzado en 1946). Es curioso como ni siquiera menciona la existencia de negociaciones cinematográficas en el capítulo que dedica a su período de embajador en Madrid, lo que inevitablemente genera suspicacias en distintas direcciones, como el auténtico papel jugado por el entonces embajador (quizás demasiado intenso para su cargo), la «corrección» de su especial interés en ellas o, porqué no, un malestar con el acuerdo conseguido que le habría llevado a eliminar cualquier alusión a su participación en las conversaciones. GRIFFIS, op. cit., pp. 268-307.

45 ACME-5562. Alba volvería a mostrar una gran cercanía hacia la MPEAA en las negociaciones para el convenio de marzo de 1959. 
negociaciones por Comercio y enfrentado a sus superiores y parte de la industria por distintos motivos presentó su dimisión a finales de febrero. Su sustituto, Joaquín Argamasilla, iba a desentenderse de las negociaciones como Comercio deseaba. Estaba claro que la protección y el fomento de la producción cinematográfica española se mantenían a la cola de las prioridades del régimen.

El convenio de enero de 1952 ha sido calificado de "fantasma». ${ }^{46}$ Su tardía e incompleta implementación justifica semejante denominación. El 4 de febrero surgió el primer contratiempo. Ante el asombro de Healey, las autoridades comunicaron que el convenio no contemplaba el derecho de las majors a establecer un distribuidor exclusivo. Al poco tiempo, Elorza añadió una nueva traba que pronto dejaría en segundo lugar a la anterior. El 28 de febrero comunicó a Healey que las licencias no podían concederse - y por tanto las películas no podían importarse- mientras los contratos de franquicia entre las casas matrices y sus filiales no fuesen autorizados por las autoridades competentes (IEME y SRC). Healey, incrédulo, replicó que sus representadas habían supuesto la buena voluntad de las autoridades para permitir la concesión de las primeras licencias mientras los acuerdos elaborados fuesen estudiados y aprobados, con el fin de cubrir todos los trámites correspondientes y proceder a su explotación desde el mismo instante en que se notificase su aprobación. En cuanto a los distribuidores exclusivos, Healey comunicó que las asociadas de la MPEAA habían entendido que poseían ese derecho y que, de no ser así, no era lógico que la SRC desmintiese su creencia dos días antes de la entrada en vigor del convenio. Elorza replicó que ya había avisado de sus intenciones. ${ }^{47}$

Los anuncios de Elorza representaban un auténtico golpe bajo para la MPEAA. Era cierto que Republic y United Artists habían expuesto su aspiración a mantener el sistema de distribuidores exclusivos; aunque lo era más que el texto del acuerdo y el acta de ratificación no contenían referencia alguna sobre ello. En cuanto a los contratos, el oportunismo español era palpable, aunque se ceñía a lo acordado. El propio Eric Johnston llamó a la puerta del embajador español en Washington reclamando una rectificación. Ante la proximidad de la fecha de inicio del convenio, Healey volvió a recordar que Republic y United Artists podían boicotear el acuerdo en caso de no ver cumplidas sus expectativas y sugirió como solución la concesión de entre 6 y 7 permisos adicionales a sus distribuidores exclusivos. Elorza se negó. ${ }^{48}$ El primero de marzo llegó, pasó y el convenio no se puso en marcha.

¿Por qué las autoridades habían retrasado sus pegas hasta una vez firmado el acuerdo? Todo parece indicar que este rechazo estaba planificado con un objetivo: retrasar o impedir la entrada en vigor del convenio. Conseguido el efecto propagandístico de su firma, lo cierto es que la administración evidenció

46 Pozo Arenas, S.: La industria del cine en España. Barcelona, Anthropos, 1983, p. 49; Díez PUERTAS, op. cit.

47 ACME-5562.

48 ACME-5563 y AGA, MAE-12300 
un más que escaso interés por cumplir lo acordado. ¿Los motivos? Básicamente dos: el desprecio hacia la corporación norteamericana, ante la que sólo se había cedido debido a las amenazas encubiertas de Griffis (los diplomáticos entendían humillante tener que negociar a la defensiva con una corporación privada); y la contradicción de algunas de las concesiones realizadas con la política comercial del estado, en concreto con las transferencias. Todo ello sin olvidar la traumática transición que podía significar para la producción nacional el cambio de un sistema de importación a otro en tan breve tiempo. La sustitución de Alba por Argüelles y el hecho de que Elorza se hiciese con las negociaciones habían significado toda una declaración de intenciones que los norteamericanos no supieron interpretar. Recordemos que Elorza había compartido las negociaciones con la rocosa dupla Suñer-Galainena.

Mientras los primeros contratos de franquicia empezaron a llegar al IEME, los desencuentros entre Elorza y un desbordado Healey comenzaron a ser el pan de cada día. El interlocutor norteamericano trató de recuperar la iniciativa aduciendo que la cláusula $\mathrm{X}$ (referente la importación temporal del material cinematográfico necesario para la puesta en explotación de las películas), había sido incluida con el propósito de atender a una situación como la planteada. Elorza hizo oídos sordos. ${ }^{49}$ En los meses siguientes las discusiones fueron concentrándose en los contratos de franquicia entre filiales y las majors. Las divisas y su gestión habían sido centrales durante las negociaciones por parte española, por lo que las autoridades no estaban dispuestas a ceder un ápice en sus pretensiones de control absoluto del tráfico monetario. Un punto preocupaba sobre los demás: los porcentajes de beneficios reservados -y por tanto transferibles - a la casa matriz. Al contrario que con el acuerdo cinematográfico, la administración pretendía que el contenido de los acuerdos de franquicia fuese lo más claro y conciso posible.

A finales de abril, SRC e IEME sólo habían recibido 4 de los contratos solicitados. Salvando consideraciones de tipo secundario, un primer informe apuntaba un par de modificaciones fundamentales a introducir en el cuerpo de los contratos. Se trataba de dos medidas en una misma línea: evitar que las casas matrices retirasen más divisas de las permitidas por medio de argucias legales o regates administrativos. La primera consistía en asegurar que el material complementario importado para la explotación corriese a cuenta de los primeros rendimientos de cada película. Tras ello podría llevarse a cabo la división de beneficios entre matriz y filial en el porcentaje establecido. La segunda giraba en torno a la diferente situación fiscal de Paramount Films respecto al resto de las filiales. Esta empresa, que había reabierto sus oficinas tras la firma del acuerdo, no se había constituido como sociedad española, sino que figuraba como sociedad extranjera con sus actividades en España. El hecho es que un informe sugería que sus dividendos debían atenerse a las normas a las que esta-

\footnotetext{
49 ACME-5563.
} 
ban sujetos los beneficios de capital estadounidense, lo que conllevaba un mayor control de los movimientos que el estipulado para las filiales..$^{50}$

Al poco tiempo el IEME comunicó que sólo aceptaba dos de los contratos. A mediados de mayo McCarthy se desplazó nuevamente a Madrid para entrevistarse con agentes del servicio de inspección del IEME. Los delegados del organismo pretendían la creación de un contrato uniforme, algo claramente lejano de la realidad, dado las considerables diferencias en la situación fiscal y el volumen de negocio entre las filiales. Evidentemente, McCarthy se negó. Constatada su firmeza, el IEME presentó los mínimos exigidos a los contratos de franquicia: gastos de entrada y puesta en circulación de las películas por cuenta de la productora americana o, al menos, cargados a las películas; no más de un sesenta por ciento de los dividendos para las casas matrices en la distribución de películas en blanco y negro; no más de un setenta por ciento en el caso de las películas en color; mención explícita al plazo de explotación de todas las películas por 5 años; y constancia contractual de que todas las cantidades resultantes a favor de la casa matriz fuesen sometidas a las condiciones de la cláusula XI del acuerdo. ${ }^{51}$

El 22 por la tarde McCarthy se entrevistó con Argüelles. El representante norteamericano creyó obtener un compromiso verbal para establecer un período de prueba en los contratos de franquicia tal y como habían sido presentados, aplicables a la primera remesa de películas establecida por el convenio. Estaba equivocado. El tiempo transcurrió y a finales de mayo el IEME no había autorizado ningún contrato. Healey volvió a inquirir a Elorza acerca del motivo del retraso ante lo que él consideraba mínimas diferencias. Elorza contestó con su silencio. A mediados de junio, sólo Radio y Paramount poseían el visto bueno a sus contratos de franquicia. Healey pidió a Elorza que al menos se aplicase a estas empresas el contenido del artículo X y se acelerase la decisión sobre el contrato entre United Artists y CB Films (los contratos exclusivos habían acabado siendo aceptados por Comercio ante la percepción de que la fórmula resultaba más ventajosa para las arcas del estado que para las filiales). Entre mediados de junio y el primero de agosto ningún contrato de franquicia fue aceptado. ${ }^{52}$

En plena tensión negociadora, la productora española Producciones Internacionales Cinematográficas (PROICI) planteó una propuesta novedosa a la administración: el rodaje de 8 «grandes» películas en coproducción con compañías norteamericanas en un plazo de tres años, utilizando como fuente de financiación los fondos bloqueados. Los derechos de distribución se repartirían entre las dos partes: para los países de habla anglosajona los derechos corresponderían a la compañía norteamericana; en el resto del mundo a la española. El IEME recomendó

\footnotetext{
50 ACME-5563.

ACME-5563.

52 ACME-5563.
} 
la no aceptación porque interpretó que la operación no generaría divisas. ${ }^{53}$ Aunque la proposición no prosperó, si que adelantó la fórmula del desbloqueo de fondos destinados a la producción, método que se plasmaría en el siguiente acuerdo y se aplicaría a gran escala a partir de finales de los cincuenta.

En los cinco meses transcurridos desde la fecha propuesta para el comienzo del convenio, sólo se habían importado 29 films, todos bajo el régimen anterior. De ese contingente, sólo 7 correspondían propiamente a las filiales, de las cuales Warner, Fox y Paramount no habían importado película alguna (si bien la distribuidora de la desaparecida Emisora Films, Femi Films, había importado 12 películas de la $F o x$.

La demora llevó a McCarthy a reclamar una solución inmediata ante Arburúa. ${ }^{54}$ En esta ocasión, Comercio si movió ficha. El 16 de julio, en una orden conjunta con Información y Turismo, se decretó la entrada en vigor del sistema de importación establecido en el convenio. El mes siguiente se realizó la sustitución definitiva del antiguo sistema de protección, dando paso a la financiación del Fondo de Protección a la Cinematografía a través de las tasas estipuladas en el convenio. La jugada tomó por sorpresa a la MPEAA. A primeros de ese mes, únicamente Radio y Paramount cumplían los requisitos administrativos para participar del convenio. La administración concedió a ambas empresas los permisos que les correspondían según el reparto realizado a finales de febrero. Las otras filiales deberían esperar a ver aprobados sus contratos. Elorza sí aceptó la concesión de licencias a favor de CB Films. También fueron concedidas las licencias reservadas a las distribuidoras nacionales. ${ }^{55}$

Elorza marchó de vacaciones a primeros de agosto, dejando las conversaciones en manos de subordinados y funcionarios del IEME. Durante su ausencia se alcanzó un principio de acuerdo en los contratos de franquicia de Universal y Columbia, así como importantes avances en el de Warner. Ante la cercanía de la temporada alta cinematográfica, con inicio en septiembre, Healey demandó una muestra de buena voluntad a sus homólogos: la concesión de permisos adicionales de importación. Elorza, ya de vuelta, se negó. Casi de inmediato, el IEME comunicó que su objetivo volvía a ser el establecimiento de un contrato uniforme para todas las franquicias. También exigía que el porcentaje de beneficios a favor de la casa matriz no excediese el cincuenta por ciento. Aunque Healey desesperaba, la corporación, que había estrenado sede en Madrid en agosto, no se quedó de brazos cruzados. Las productoras con filiales hicieron imposible la compra de su material a las distribuidoras locales, bien ofreciendo sus películas menos «comerciales» (serie B), bien exigiendo precios elevadísimos. Quedaba claro que si la MPEAA no podía explotar sus licencias, no iba a permitir que otros lo hiciesen. A mediados de septiembre sólo 3 de las

\footnotetext{
53 AHBE, IEME-8.

54 ACME-5563.

55 ACME-5562 y 5563.
} 
8 distribuidoras españolas beneficiarias habían ejecutado su opción, siendo una CB Films. Los empresarios iban a reclamar el amparo de su gobierno. ${ }^{56}$

La situación permaneció estancada hasta noviembre. A principios de mes, Healey solicitó nuevamente permiso de importación temporal para las empresas que no habían visto aceptados sus contratos de franquicia. Elorza volvió a negarse. Healey y McCarthy reaccionaron cargando contra su interlocutor. ${ }^{57} \mathrm{La}$ sucesión de encontronazos y la actitud desafiante de Elorza habían sumergido las conversaciones en una dinámica de enfrentamiento personal. Ante el peligro de que la refriega fuese a más, Argüelles optó por relevar a Elorza. José Antonio Giménez Arnau, diplomático y técnico comercial de Estado, fue su sustituto. La misión que se le encomendó no era precisamente sencilla: reconstruir las relaciones con la MPEAA por un lado; y negociar un acuerdo más beneficioso para España por el otro.

La primera entrevista entre Healey y Arnau tuvo lugar a mediados de diciembre y contribuyó a entablar una buena relación entre ambos interlocutores. Las dos partes pusieron las cartas sobre la mesa. Arnau argumentó que la dilación en la implementación del acuerdo se debía a la dejadez norteamericana en el asesoramiento sobre la distribución de películas españolas en el extranjero y, sobre todo, al desentendimiento en la gestión del crédito de 350.000 dólares, lo que probablemente era una de las condiciones de Información y Turismo para aceptar el segundo plano que había adoptado en las negociaciones desde la salida de García Escudero. Dado ese paso, Arnau dejó entrever que su ministerio se mostraría más receptivo a las demandas norteamericanas. McCarthy advirtió que en tanto en cuanto las filiales no fuesen autorizadas a importar las 60 películas estipuladas por el convenio vigente, ninguno de los compromisos adquiridos iba a ejecutarse, por no hablar del inicio de nuevas negociaciones. ${ }^{58}$

Mientras tanto, la industria española continuaba a la expectativa. Durante los cinco primeros meses trascurridos desde la aplicación unilateral del convenio se habían importado 42 de las 100 películas acordadas: 32 por las filiales; 4 entre CB Films (United Artists) y CEPICSA (Republic); y 6 por distribuidoras españolas independientes. En el mismo período habían sido importadas otras 23 películas bajo el teóricamente anulado régimen anterior: 6 por las filiales y el resto por distribuidoras independientes españolas, 9 de ellas por Femi Films. Pero la importación no implicaba la explotación de las películas, puesto que las filiales no ponían todas en circulación para agravar la situación de la industria española. En un escrito de primeros del nuevo año los exhibidores se dirigieron a Arnau para describir la situación propiciada por la escasez de películas norteamericanas, que les llevaba a reestrenar películas una y otra vez «en cabalgata interminable e irritante» ante la ausencia de material de estreno. A pesar del au-

\footnotetext{
56 ACME-5563.

57 ACME-5563.

58 ACME-5562 y 5563.
} 
mento de films procedentes de otros países (sobre todo mexicanos), los exhibidores se escudaban en que los reestrenos seguían siendo más rentables que el resto de películas extranjeras, que, en muchos casos, ni siquiera estrenaban. El sector reclamaba un aumento del número de importaciones norteamericanas hasta 150 anuales porque "el gusto y la preferencia del público así lo han decidido».59 Su alineación del lado de la MPEAA se hacía más evidente si cabe.

\subsection{Las negociaciones de Nueva York.}

En un intento de encarrilar la situación y con el respaldo de sus superiores, Arnau favoreció el reconocimiento de los contratos de franquicia restantes y completó casi de golpe el cupo de 60 películas. Ante semejantes gestos, las partes se pusieron de acuerdo en prorrogar el convenio vigente a la siguiente temporada (es decir, de marzo de 1953 a febrero de 1954), bajo el compromiso de negociar uno nuevo. En pocos meses los españoles habían cambiado radicalmente su actitud. Las causas habría que buscarlas, de nuevo, más allá de la propia dinámica de las negociaciones, puesto que las reclamaciones de los exhibidores no parecían suficientes para provocar semejante giro. La aceleración de las negociaciones bilaterales, en su recta final, pudieron aconsejar a los estrategas del régimen a demandar ante Arburúa una relajación de las tensiones con la influyente corporación norteamericana. Pese a las concesiones de última hora, la MPEAA tenía motivos más que justificados para desconfiar de las cambiantes intenciones españolas.

Ante la insistencia española las conversaciones se desplazarían a Nueva York, dando la vuelta a la situación de hace dos años, cuando Arburúa había rechazado la invitación de la MPEAA para negociar en la ciudad norteamericana. El cambio de actitud sólo podía entenderse bien porque Arnau le era de plena confianza y Alba no; bien porque se quería instrumentalizar propagandísticamente un hipotético acuerdo sellado en Estados Unidos; o bien por la necesidad que sentía el ministro de alejar a Arnau de las presiones generadas por la industria. ${ }^{60}$

Muy en su papel secundario posterior a la salida de García Escudero de la DGCT, Información y Turismo se comprometió a respaldar a Arnau, reclamando a cambio insistencia en el asunto del crédito. Sin embargo, la principal labor que se encomendó a Arnau fue la reforma del sistema de transferencias acordado el año anterior. La disponibilidad de divisas de la economía española había comenzado a declinar nuevamente a principios de año. Ante la ausencia de liquidez, desde el IEME y el SOEC se estaban planteando imaginativas operaciones de compensación para cubrir las obligaciones con Hollywood: desde autorizar a las filiales a vender pesetas con una prima sobre el cambio oficial a

\footnotetext{
59 ACME-5562.

60 ACME-5562.
} 
compañías norteamericanas recientemente interesadas en España y a la Embajada, embarcada en la construcción de la nueva residencia en Madrid; pasando por la cesión a las productoras norteamericanas de la totalidad o una parte del precio de la venta en dólares de una serie de productos españoles potencialmente exportables, como la alta costura; hasta la concesión a las filiales del derecho a construir salas de exhibición en Madrid y Barcelona. ${ }^{61}$

Durante los preparativos del viaje surgieron algunos problemas. Aprovechando que Healey se encontraba fuera de España, Arnau impulsó la creación de una cuenta bancaria a nombre de cada compañía norteamericana, regulada por el artículo XI del convenio y bajo la supervisión del IEME. En esa cuenta, tras la deducción de los impuestos correspondientes, se ingresarían los fondos procedentes de la explotación de las películas importadas bajo el régimen en vigor. Esta medida pretendía fortalecer el control sobre las transacciones. La MPEAA lo entendió como una pérdida de control sobre sus beneficios. A su vuelta, Healey advirtió que el asunto revestía mayor importancia que la negociación de un nuevo convenio. En el fondo de semejante decisión residía la intención española de corregir el contenido de la cláusula XI, que estipulaba que los beneficios destinados a la parte de la productora fuesen directamente plasmados en la cuenta de Nueva York de las compañías correspondientes, siendo transferida su cuantía por el gobierno cuando la disposición de dólares lo permitiese. Semejante operación vulneraba la legislación española acerca del uso de fondos por extranjeros (regulada por el «decreto 313»), que prohibía la libre disposición de saldos en pesetas existentes en cuentas a favor de titulares residentes en el extranjero. Según el IEME, la redacción de la cláusula XI permitía a las productoras norteamericanas violar esas disposiciones gracias a la ficción jurídica generada por el hecho que las filiales fuesen sociedades españolas, y la ficción contable que representaba la existencia de una supuesta cuenta acreedora inmóvil del cedente norteamericano que, sin embargo, podía ser gestionada desde Estados Unidos. El IEME defendía que el ingreso de las cantidades adeudas a las compañías en un banco español representaba una garantía de correcta gestión ante la evidencia de movimientos fuera de la ley de los fondos de las empresas norteamericanas, como habían demostrado pagos detectados con carácter de «auxilio familiar». El objetivo era lograr el compromiso de las compañías para poner al corriente a SOEC e IEME de la formación de los fondos, así como de los ingresos y gastos a su cargo. La delegación española entendía que la inclusión del siguiente párrafo en un futuro convenio atajaría el problema:

«Los fondos que a favor de los cedentes norteamericanos de las películas resulten como consecuencia de lo expuesto en el párrafo anterior, serán ingresados en una cuenta bancaria a nombre del beneficiario americano» 62 .

$61 \quad$ ACME-5562.

62 ACME-5562. 
Arnau se desplazó a finales de abril a Estados Unidos. En la primera reunión presentó el proyecto consensuado por los dos ministerios. El borrador contemplaba un cupo de 75 películas dobladas al castellano e importación ilimitada de películas en versión original repartidas «3 a 2» a favor de las filiales. La suma de películas dobladas de otros países no podría exceder a la de las norteamericanas. Se sustituiría el permiso de importación por un derecho de doblaje, que se pagaría en función del tipo de soporte utilizado y el tamaño de la películas: en blanco y negro, 650.000 pesetas; en color, 910.000. Las licencias podrían ser solicitadas durante todo el período de vigencia, eliminando el sistema de entrega escalonado que había indignado a la MPEAA. Las películas podrían ser estrenadas en años posteriores a la temporada de obtención de la licencia. Las transferencias se harían del mismo modo que la cláusula XI del convenio vigente. Por si fuera poco, la MPEAA debía comprometerse a mantener su promesa de gestión del crédito de 350.000 dólares para la temporada 1952-53, así como de otro crédito de la misma cuantía para la temporada 1953-54. El convenio regiría por un año, entre el 1 de agosto de 1953 y el 31 de julio de $1954 .{ }^{63}$

Ralph Hetzel, vicepresidente de la corporación, se negó a aceptar semejantes proposiciones y presentó una ambiciosa contrapropuesta: extensión del acuerdo por dos años; aumento del cupo anual hasta 160 películas de largo metraje dobladas más el doble de cortos; concesión simultánea y reducción de los cánones hasta 500.000 pesetas por película (400.000 en la segunda temporada) y permiso para doblar películas en España y exportarlas al mercado latinoamericano; trato equitativo a todas sus asociadas; derecho de las compañías a comprar las licencias no ejecutadas por las distribuidoras españolas; obligación a que la totalidad de las licencias fuesen cubiertas con anterioridad al décimo mes del acuerdo y, en el caso de no ejecutarse, devolución al gobierno español para su libre redistribución; supresión de cualquier tipo de limitación a la importación temporal; derecho a establecer los acuerdos de franquicia deseados; derecho a abastecerse por cuenta propia de película virgen en caso de problemas del gobierno español para cubrir su demanda. ${ }^{64}$

Las dos partes parecían adoptar nuevamente posiciones antagónicas. Arnau decidió hacer una serie de concesiones en cuanto al cupo (más películas) y el canon de importación y doblaje (más cerca de la oferta norteamericana), aunque en compensación exigió un crédito de 500.000 dólares, además de introducir el párrafo propuesto por el IEME sobre el control de las transferencias. La apuesta representaba todo un órdago. Contra pronóstico, los norteamericanos se mostraron dispuestos a aceptarla si se introducían varias puntualizaciones: una reformulación del artículo referente al cupo, garantizándose el estreno de 100 largometrajes para la temporada corriente en base a la importación de 75

63 AMAE, R-3082/36 y ACME-5562.

64 ACME-5563. 
largos, cortos y medio metrajes en un período estipulado y al estreno de 25 largos ya importadas; la rebaja del precio de las películas de largo metraje en blanco y negro hasta 600.000 pesetas y el aumento de las de color hasta 750.000; y garantía de una transferencia mínima anual de dólares a las compañías norteamericanas (Arnau barajaba una cifra en torno a 15.000 dólares mensuales). La alegría de Arnau ante sus avances pronto se tornó desilusión. Argüelles comunicó a su subordinado que «de cifra para transferencia el ministro no quiere ni oír hablar». La negativa en este punto dejó malheridas las negociaciones, que deambularon unos días más hasta suspenderse de mutuo acuerdo el 21 de mayo. La estocada definitiva fue la negativa de la MPEAA a introducir como cláusula la obtención del crédito. Sumamente decepcionado, Arnau propuso importar películas de productores independientes, algo que podría haber discutido con el presidente de la SIMPP durante su estancia en Estados Unidos. Arnau confesaba a su inmediato superior que, sin embargo, «para ello hace falta una posición de firmeza, y eso es lo que me asusta un poco». La coyuntura bilateral seguía pesando mucho. El día 25 Hetzel resumió las condiciones que su organización exigía ver satisfechas si el gobierno español quería un acuerdo: negativa a la inclusión del crédito como cláusula; reducción o congelación del precio de las licencias de doblaje; garantía de un flujo fijo de transferencias en dólares; y permiso a las compañías para vender libremente pesetas a cambio de dólares a organismos oficiales o trabajadores del gobierno de Estados Unidos. ${ }^{65}$

Al poco tiempo, Arburúa impulsó una nueva oferta sobre la base de 75 películas por temporada y la renuncia al crédito a cambio de la elaboración por cada una de las productoras norteamericanas de un documental turístico sobre España en technicolor (lo que había ofrecido la MPEAA en 1950). Para acallar voces críticas en la industria, el ministro concedió 500 millones de francos y 200.000 dólares para la mejora y adquisición de infraestructuras y material cinematográfico. ${ }^{66} \mathrm{La}$ ausencia de cualquier referencia a un compromiso sobre las transferencias fijas mediatizaba enormemente la posibilidad de que se cerrase un acuerdo. La MPEAA rechazó la oferta.

\subsection{El segundo convenio y la «pax» cinematográfica.}

En el mes de agosto y ante la insistencia de Arburúa, Arnau probó con una nueva fórmula: ofreció a cada una de las filiales 6 permisos de importación, cuyos beneficios serían transferidos en dólares a partir del primero de octubre. La jugada no le salió bien. Las compañías se negaron y Eugene Van Dee, sustituto de Healey, le reprochó el intento de dividir a las compañías. Ante las reiteradas negativas de la corporación, escarmentada de los incumplimientos es-

65 ACME-5562 y 5563.
66 ACME-5562 y 5563. 
pañoles, Arburúa decidió tensar la cuerda y concedió un cupo de 30 permisos de importación a las distribuidoras españolas, cifra que sería completada con un cupo similar a finales de año. Comercio avalaría su pago en dólares. El órdago tenía dos claros objetivos: demostrar a la MPEAA que el gobierno español no estaba dispuesto a firmar cualquier cosa (por el momento); y, en lo que era un guiño al contexto bilateral, demostrar que España pretendía seguir importando películas norteamericanas y, que si había problemas, éstos eran debidos a la actitud de la corporación. ${ }^{67}$

Entre el 21 y el 27 de septiembre se celebró la Primera Semana Internacional del Cine de San Sebastián. A imitación de los festivales de Venecia o Cannes, el régimen franquista pretendía utilizar el certamen como escaparate de una España moderna y abierta al exterior. Conseguir que las estrellas del celuloide paseasen por La Concha del lado de las autoridades ante las cámaras de medio mundo, era un objetivo muy apetecible para el régimen. Como era de prever, la MPEAA aunque participó de forma testimonial, envió una película menor y sus estrellas se quedaron en casa. Las partes tomaron nota. ${ }^{68}$

El 26 de septiembre de 1953 España y Estados Unidos formalizaron una alianza que implicaba la definitiva legitimación internacional del régimen del general Franco. Su impacto sobre las negociaciones cinematográficas iba a ser casi inmediato. La escenificación de la «amistad bilateral» sellada ese día iba a contagiarse a todos los ámbitos de las relaciones bilaterales. También al cinematográfico.

A finales de septiembre se produjo una reunión entre el jefe del SOEC y los distribuidores españoles. A lo largo de la entrevista, los empresarios mostraron su escepticismo ante la postura de fuerza promovida por Arburúa, temiendo la inmediata firma de un acuerdo a colación de la atmósfera generada por los convenios de septiembre. De paso, recordaron que las compañías norteamericanas estaban imposibilitando el alquiler de sus películas al exigir precios muy elevados. También reclamaron un mayor apoyo de la banca privada y la garantía del gobierno de conceder los dólares necesarios para la importación. ${ }^{69}$ Arnau hizo caso omiso y sus temores no tardaron en confirmarse.

Arburúa y Argüelles reforzaron la posición de Arnau nombrándole al frente de la agencia que debía gestionar los recursos económicos movilizados por los pactos: la Dirección General de Cooperación Económica (DGCE). El objetivo era claro: vincular las negociaciones cinematográficas al resto de las relaciones comerciales bilaterales. No debió tener mucho efecto, porque el convenio de doce cláusulas alcanzado en Madrid el 21 de noviembre de 1953 contemplaba

67 ACME-5562.

68 La película que representó a Estados Unidos fue «Los Crímenes del Museo de Cera» (Warner Brothers), y no «Duelo al Sol», como estaba anunciado. Tampoco acudieron, a pesar de los anuncios oficiales, Merle Oberon, Ingrid Bergman, Gary Cooper, Tyrone Power ni Kirk Douglas. Ver Primer Plano, año XIV, números 675 y 676.

69 ACME-5562. 
numerosas cesiones gratuitas a los norteamericanos ${ }^{70}$. La ausencia de documentación referente a la negociación de este acuerdo en los archivos españoles viene a confirmar la excepcionalidad e incluso el secretismo que lo rodeó.

El texto del convenio da pistas de porqué semejante secretismo. A primera vista resaltaba la ausencia de cualquier referencia a la concesión e incluso gestión de un crédito para la industria española (teniendo en cuenta la anterior insistencia española), así como una mayor simplificación y concreción de anteriores puntos de discordia, como los referidos a los contratos de franquicia o las transferencias. Destacaba la especificación de una fecha de inicio para las importaciones con el objetivo de evitar modificaciones unilaterales como la ejecutada el año anterior (artículo II). También llamaba la atención la exclusión de la SIMPP del acuerdo. Las novedades en cuanto al cupo fueron la inclusión de 100 cortos, formato que estaba revalorizándose ante el éxito de los dibujos animados (III) y, sobre todo, la inclusión de una cláusula específica haciendo referencia a la posibilidad del establecimiento de un cupo extraordinario (IV). La fórmula brindaba a la delegación española la posibilidad de ofrecer la imagen de que no se había aceptado un aumento del contingente, así como de contentar las aspiraciones norteamericanas de un aumento del cupo sin comprometer una cifra determinada. Las cantidades de los permisos estaban en la línea de las cifras máximas propuestas por la corporación en las conversaciones de Nueva York (V). Entre las concesiones «menores» que arrancó la MPEAA destacó el permiso a las casas americanas a abastecerse por sí mismas de material virgen (VII). Las modificaciones más relevantes se presentaron en la cláusula referente al manejo de los fondos y las transferencias de divisas de las filiales a sus casas matrices (IX). Se podía afirmar que el visto bueno de la asociación de colocar sus fondos bajo el control del IEME, así como la estipulación de que más de la mitad de ellos deberían ser empleados en España en determinados aspectos como la producción de películas, fueron concesiones aceptables a cambio del compromiso español a efectuar transferencias trimestrales, que, aunque no aparecía en el texto del acuerdo, se fijaron en 50.000 dólares a repartir entre las compañías. Esta medida representaba toda una excepción a la política de control de divisas seguida por Comercio. El convenio debería permanecer en vigor entre e 11 de junio de 1954 y el 1 de mayo de 1955 (I).

Tras la firma del acuerdo, el periodo que se abrió entre los meses de noviembre de 1953 y 1954 supuso todo un oasis de paz y calma en las conflictivas relaciones cinematográficas bilaterales. El correcto funcionamiento del convenio propició una atmósfera de colaboración desconocida hasta la fecha. Del anterior clima de tensión y desconfianza se pasó, de la noche a la mañana, a la colaboración y comprensión mutua. Nuevamente, la industria de Hollywood

70 Así lo hace entender Griffith Jhonson en su carta de agradecimiento y despedida a Arnau, Madrid, 25 de noviembre de 1953. ACME-5562. 
volvió a coquetear con el régimen franquista tras años de alejamiento, ${ }^{71}$ y majors como Universal siguieron los pasos de Columbia y Fox, eligiendo Barcelona como sede de sus convenciones anuales. Además, a partir del verano de 1953, la llegada masiva de actores a España se convirtió en el espectáculo mediático por excelencia de la prensa española, sedienta de noticias frescas sobre las estrellas hollywoodienses.

El principal obstáculo para la ejecución del convenio fue la regulación de las cuentas de las filiales, su puesta al día y liquidación en los casos necesarios. El acuerdo preveía la creación de dos cuentas, una para los fondos bloqueados en España (sesenta por ciento de los rendimientos) y otra para los fondos transferibles a la casa matriz (cuarenta por ciento). El texto contemplaba que los beneficios obtenidos de las importaciones bajo el régimen anterior, es decir, los de las temporadas 1952/53 y 1953/54, fuesen gestionados bajo el artículo IX. Para finales de 1953 se había realizado la puesta al día de los fondos en pesetas de las filiales que, a continuación y tras su división acorde a los porcentajes estipulados, pasaron a constituir las cuentas mencionadas. ${ }^{72}$ Las cuentas provenientes de fondos en pesetas anteriores al Convenio de enero de 1952 eran escasas y permanecían bajo control estricto del IEME, por lo que no fueron consideradas un problema trascendente. ${ }^{73}$ En enero se efectuó la primera transferencia trimestral de 50.000 dólares.

La transición de un sistema a otro colocó en apuros financieros a varias de las filiales, ya que algunos de los contratos de franquicia otorgaban a las filiales condiciones onerosas (sobre todo en los porcentajes de beneficio y la distribución de los pagos a la casa matriz) que, en muchos casos, eran incapaces de cumplir. Van Dee se desplazó a España a primeros de año para tratar de resolver los problemas junto a Arnau y Pastor. Durante sucesivas entrevistas, los interlocutores determinaron el funcionamiento de la gestión de las cuentas que, a propuesta de los norteamericanos, pasaron a denominarse « $\mathrm{A}$ » (la dispuesta para las transferencias) y «B» (la congelada). Además, se alcanzaron otros importantes acuerdos, como la forma de realizar las operaciones de compensación

71 Como mejor ejemplo, sirva la recepción por todo lo alto con la que Jack Warner obsequió al embajador Lequerica durante su viaje por California en febrero de 1954. APG, JE-1681/19.

72 En concreto, fue el 26 de diciembre de 1953 cuando el Negociado de Inspección del IEME presentó a la Dirección del Instituto las cantidades figurantes en los libros contables de las siete filiales. A la cabeza de ganancias se encontraba MGM Ibérica, con más de 17.000.000 pesetas; le seguían a distancia Universal y Paramount con más de 7.000.000, Warner e Hispano Fox con más de 4.000.000 y, a la cola, Columbia y Radio con poco más de 1.500.000. El estudio aceptado para la operación, de fecha 24 de febrero de 1954, incrementó la cifra de $M G M$ hasta más de 23.000.000, la de Hispano Fox a más de 5.000.000 y, por el contrario, redujo la de Radio a poco más de 300.000 . AHBE, IEME-24.

73 Estas cuentas, procedentes en su mayoría de operaciones de compensación con vino y corcho en los últimos años de la Segunda Guerra Mundial, eran de escasa cuantía, permanecían prácticamente inmovilizadas y, además, el IEME no las reconocía como deuda a Estados Unidos. AHBE, IEME-24. 
con las cuentas «A»y «B»; el tipo de cambio aplicable (cambio oficial) a las remesas trimestrales y su libre reparto por la MPEAA entre sus asociadas (incluidas United Artists, Republic y Monogram); y el modo en que las filiales con más problemas (Radio y Columbia) debían efectuar los depósitos bancarios. ${ }^{74}$ Las diferentes compañías fueron abriendo las cuentas a nombre de sus casas matrices en las sucursales de Barcelona de los principales bancos que operaban en España.

Desde el inicio de las negociaciones en 1950, el SNE y los distintos sectores afectados, sobre todo la producción, habían alzado la voz en defensa de sus intereses. Ahora, sin embargo, el ambiente parecía calmado. Podía haber motivos para ello. En paralelo al pico alcanzado por importaciones y estrenos de películas norteamericanas en 1954, se produjo un aumento considerable de los rodajes y estrenos nacionales. Semejante crecimiento había sido espoleado por el incremento de los ingresos en el Fondo de Protección a la Cinematografía que se venía produciendo desde 1953, principalmente por el aumento de importaciones norteamericanas. El sector que peor lo pasó durante el período fue el de la distribución. Aunque el acuerdo les había reservado un cupo de 40 películas, los precios exigidos y la ínfima calidad de las películas ofrecidas (en incumplimiento de lo acordado), impidió que estas compañías pudiesen cubrir el contingente asignado. Eso sin contar con las maniobras de algunas majors para que las distribuidoras pagasen en dólares. El sector y el SNE, sin embargo, permanecieron en silencio.

La apuesta de las autoridades por el nuevo sistema parecía firme. De hecho, se practicó una política de tolerancia cero hacia las importaciones ilegales, que sin embargo no evitó la pervivencia de oscuras operaciones. Tras los primeros contactos, sólo surgieron pequeños problemas con los contratos exclusivos de Republic y United Artists, aunque fueron resueltos sin dilación. ${ }^{75} \mathrm{~A}$ finales de abril y agosto Comercio realizó las transferencias correspondientes, lo que sumaban un total de 150.000 dólares transferidos desde la firma del convenio. En ese momento, Argüelles y probablemente el propio Arnau consideraron que era hora de que el último se dedicase en exclusiva a la DGCE, desde la cual había gozado de una panorámica privilegiada de las operaciones de compensación realizadas como pago complementario a las compañías norteamericanas. ${ }^{76}$

74 ACME-5562.

75 AHBE, IEME-24. El IEME juzgó negativamente todas las propuestas de importación de películas americanas bajo regímenes ajenos al convenio, como una propuesta de «intercambio con producción española» de tres películas americanas, es decir, el procedimiento que había sido suprimido en 1952 tras la corrupción y bolsa negra que había generado durante los once años que estuvo en vigor.

76 Las operaciones de compensación aumentaron significativamente tras el acuerdo de noviembre, sobre todo por parte de las compañías con mejores resultados en España. Un ejemplo son las operaciones para la importación de material técnico para la exhibición de películas en cinemascope. AHBE, IEME-24. 
De esa misma perspectiva había disfrutado su sustituto al frente del SOEC, Ramón Serrano Guzmán, técnico comercial, diplomático y segundo de Arnau en la DGCE.

La sintonía entre las partes tuvo un capítulo muy representativo entre el 24 y el 31 de julio. En esta ocasión, al contrario que al año anterior, el lujo y el glamour de Hollywood sí que se dejaron notar en el Primer Festival Internacional del Cine de San Sebastián. La MPEAA participó activamente con «The Black Shield of Falworth (Universal) y el corto «The New Venezuela» (Fox); y una de sus estrellas, Gloria Swanson, acudió al certamen, como se encargarían de inmortalizar las fotografías junto a Carmen Polo de Franco. Por si fuera poco, en noviembre, en reunión celebrada en Madrid, la Federación Internacional de Productores de Films (FIAPF), marioneta de la MPEAA, encumbró al certamen a la categoría «A» o de competición, es decir, al mismo nivel que Cannes o Venecia tras apenas dos años de existencia. Lo cierto es que a parte de prebendas más o menos acordadas, la corporación tenía un cierto interés económico en su participación en el festival, puesto que las películas importadas para este tipo de eventos estaban exentas de cualquier tipo de canon en su posterior comercialización. ${ }^{77}$ Aunque carecemos de pruebas documentales que lo atestigüen, no es de extrañar que los negociadores españoles incluyesen la participación activa de Hollywood en el festival como una de las contraprestaciones de la corporación a los privilegios obtenidos.

El anuncio del rodaje en España de la superproducción «Alejandro el Magno» por United Artists y CB Films confirmó el idilio. Como estipulaba el artículo IX, la financiación correría a cargo de los fondos depositados en las cuentas B. ${ }^{78}$ Semejante decisión representó un hito para la presencia del cine norteamericano en España. Los ejecutivos de Hollywood, acuciados por la creciente conflictividad laboral e interesados en la realización de grandes superproducciones al aire libre (blockbusters) con las que diferenciarse de los contenidos ofrecidos por la televisión, identificaron en España el lugar ideal para sustituir a Italia como escenario de sus superproducciones. La diversidad paisajista y climática que ofrecía la península Ibérica brindaba un marco inmejorable para ese tipo de films. Los bajos salarios y calidad de los técnicos españoles y los cuantiosos fon-

77 ACME-5562. «The Black Shield of Falworth» o «Coraza negra» fue rodada en el moderno sistema cinemascope y contaba como pareja protagonista con el estelar matrimonio compuesto por Tony Curtis y Janet Leigh. La junta directiva de la FIAPF decidió que en el certamen donostirra se concediese a partir de 1955 el «Premio Internacional del Color».

78 AHBE, IEME-24. La película fue dirigida por Robert Rossen en los estudios de Sevilla Films. No fue casual que United Artists eligiese España como plató. Como se demostraría durante el posterior boicot, la empresa mantenía una relación privilegiada con las autoridades españolas a través de $C B$ Films. En 1956, en pleno boicot de la MPEAA, la compañía filmaría otra superproducción, «The Pride and the Passion», con James Stewart, Frank Sintra y Sofia Loren en el reparto. Existe un acercamiento algo superficial a las primeras producciones norteamericanas en España: HerEDERO, C., Las buellas del tiempo, cine español 1951-1961, Valencia, Filmoteca de la Generalitat Valenciana, 1993, pp. 108-109. 
dos bloqueados favorecían la financiación del star system y los grandes decorados. Por si fuese poco, la reciente firma de los convenios bilaterales garantizaba la colaboración del régimen. La suma de circunstancias favorables representaba una tentación difícilmente rechazable para las majors. Sólo el conflicto iniciado a finales de 1954 entre la MPEAA y el gobierno español retrasaría el desembarco definitivo hasta finales de la década.

A últimos de noviembre, como estaba previsto, Van Dee reclamó la concesión del contingente extraordinario contemplado por la cláusula IV. Se concedieron 14 nuevas licencias, 7 para películas largas (una por filial) y 7 para películas cortas. El propio Eric Johnston agradeció el esfuerzo realizado. La cifra total de importaciones y estrenos suponía el guarismo más elevado de toda la década. El empleo de las cuentas bloqueadas funcionó a buen ritmo. Sí el 29 de mayo de 1954 sumaban más de 53 millones de pesetas, medio año más tarde no pasaban de algo más de 31. Es decir, más de 22 millones de pesetas habían sido empleados en España, y no precisamente en gastos de producción y coproducción (el rodaje de "Alejando Magno» no comenzaría hasta 1955). ${ }^{79}$ Los desembolsos en representación, explotación y propaganda (las otras posibilidades contempladas en el artículo IX), aunque existentes, no fueron demasiado elevados. Probablemente, la mayor parte de éstos correspondieron a la coletilla «y en general» que acompañaba a la quinta de las opciones ofrecidas para el uso de las cuentas B. No es de extrañar que muchos de esos fondos se acabasen esfumando en la maraña de transacciones, intercambios y operaciones de compensación ligadas a intereses norteamericanos.

\subsection{Vuelta a las andadas.}

El 30 de noviembre debía ejecutarse una de las transferencias acordadas. Comercio no realizó el pago y pronto resultó evidente que no iba a continuar con las transferencias trimestrales (tampoco se realizaría la de febrero). La delegación española deseaba modificar el lesivo acuerdo del año anterior y tenía el visto bueno desde la Jefatura del Estado. ¿Porqué un nuevo giro? Los datos que barajamos nos hacen pensar que quizás porque, para entonces, las relaciones bilaterales gozaban de buena salud y la necesidad de complacer al "amigo» norteamericano no era tan apremiante. Al fin y al cabo, la salida de dólares por la importación de películas seguía siendo vista como un derroche ante la todavía lamentable situación de la balanza exterior española.

Los ministerios se posicionaron ante la inminencia de nuevas tensiones y negociaciones con la MPEAA. Arburúa blindó a Serrano Guzmán nombrándole Director General de Comercio, aunque apenas compaginó ambas funciones durante meses, ya que en marzo fue relevado por Guillermo Calderón al frente

\footnotetext{
79 AHBE, IEME-24.
} 
del SOEC. Por su parte, Información y Turismo iba a tratar de recuperar el terreno y protagonismo perdido. En febrero de 1955 Manuel Torres sustituyó al «inofensivo» Argamasilla al frente de la DGCT. El nuevo director iba a desplegar una política beligerante en las negociaciones con Comercio y los norteamericanos. Lo cierto es que la nueva postura de los gestores administrativos de la DCGT era en cierto modo comprensible. Para entonces era evidente que el SOEC se ocupada más de los efectos de las importaciones en la balanza de pagos que de la industria nacional. Además, las concesiones de noviembre de 1953 habían añadido a las mediocres cifras de exhibición de la producción nacional un nuevo problema: el desentendimiento de las filiales a distribuir material español, algo que se había silenciado en los meses anteriores. ${ }^{80}$ Torres diseñó una política de fomento con dos vértices. De un lado, la firma de acuerdos de intercambio y coproducción con países como Francia, Italia y la República Federal Alemana, destinados a mejorar la calidad del cine español y a disminuir el peso cuantitativo de las películas norteamericanas sobre el total de las películas exhibidas. Del otro, medidas legislativas orientadas a garantizar las distribución y exhibición del cine español. Las tensiones competenciales entre ambos ministerios por el control de la cinematografía iban a resucitar con virulencia ante la permisividad de la Jefatura del Estado.

El mismo mes de febrero, el director general de Hispano Fox planteó a Serrano Guzmán la prórroga del convenio en vigor. La MPEAA movía ficha, y lo hacía a la defensiva ante la inminencia del vencimiento del acuerdo, el creciente desentendimiento de su embajada y la hostilidad de la DGCT. César Alba «confesaba» que la corporación estaba dispuesta a admitir la fórmula de la prórroga si se aceptaban algunas enmiendas sobre el texto del acuerdo, cambios que contemplarían un leve aumento del cupo, una rebaja en el canon de importación y una mayor libertad en el uso de los fondos «A» $\mathrm{y}$ «B». No obtuvo respuesta. ${ }^{81}$

Los preparativos de las negociaciones en la delegación española fueron bastante movidos. Los informes y opiniones sobre cuales debían ser los puntos a discutir, las condiciones a ofrecer y los requisitos a exigir se sucedieron en todas las direcciones; desde los productores, que buscaban una revisión a la baja de las concesiones de noviembre de 1953; pasando por las filiales y los distribuidores exclusivos, que pedían una prórroga del convenio; hasta los exhibidores, que básicamente reclamaba un aumento del número de películas norteamericanas a importarse por temporada. Pero en esta ocasión la voz cantante la entonaría la DGCT. ${ }^{82}$

Las reuniones tuvieron lugar entre el 27 de mayo y el 1 de junio en Madrid. Por parte española acudió una amplia representación de los organismos afecta-

\footnotetext{
80 ACME-5562.

81 ACME-5562.

82 ACME-5562.
} 
dos: Calderón (SOEC), Torres (DGCT), Pastor (IEME), Casanova (SNE), Frontera (Dirección General de Aduanas) y Mestas (Dirección General de Política Económica); la delegación norteamericana estuvo encabezada por Van Dee. Los representantes norteamericanos comenzaron planteando el impago de las últimas tres transferencias trimestrales. Los españoles les acusaron de incumplir igualmente la cláusula IX, concretamente en lo referente al pago de royalties por parte de las distribuidoras nacionales (a las que se estaba forzando a pagar en dólares). Las proposiciones españolas descansaban en cuatro puntos: reducción del contingente de películas dobladas hasta 68 películas al año, completadas con 12 en versión original; incremento del canon de doblaje de aproximadamente un veinte por ciento para películas en blanco y negro y color, además de establecer una nueva categoría para las películas tridimensionales o en cinemascope, que pagarían 980.000 pesetas por licencia; obligatoriedad de las filiales a distribuir películas nacionales en España y a sus casas matrices a distribuirlas en el extranjero; y obligatoriedad de las casas norteamericanas a producir o coproducir un cierto número de películas por temporada, con objeto de emplear la totalidad de los fondos retenidos en las cuentas B. ${ }^{83}$ Los negociadores norteamericanos se mostraron dispuestos a discutir todas las propuestas salvo la obligatoriedad de las filiales norteamericanas a distribuir películas españolas. La delegación española se ratificó en sus posiciones incluso siendo consciente de que en mayo la MPEAA había declarado un boicot al mercado danés en represalia por determinadas medidas legislativas. ${ }^{84}$ Desde el SOEC se empezó a temer un nuevo boicot.

El 19 de julio, el ministro consejero de la embajada norteamericana, a petición de Eric Johnston, propuso la prórroga del convenio en vigor hasta mayo de 1956. Argüelles aceptó. En ese momento llegó a Nueva York noticia de que el 14 de julio Información y Turismo habían sancionado unilateralmente la obligatoriedad para todas las distribuidoras españolas (las filiales lo eran) a comercializar un mínimo de una película española por cada 4 films extranjeros. La medida, adoptada con la oposición de Comercio, implicaba una forzada reducción del volumen de trabajo de las compañías norteamericanas (teniendo en cuenta el número de producciones españolas), así como una intromisión sustancial en su gestión comercial. La reacción de la MPEAA fue inmediata. El 4 de agosto de 1955, Eric Johnston comunicó a Arburúa que descartaba la prórroga y que las asociadas de la MPEAA con filiales en España suspendían sus operaciones en tanto en cuanto la medida no fuese derogada. ${ }^{85}$ Las negociaciones retrocedían a la situación de mayo de 1951. El boicot se prolongaría durante más de tres años y sólo se sellaría un nuevo acuerdo en marzo de 1959, el cual para no romper la norma, pronto quedaría en papel mojado.

\footnotetext{
83 ACME-5562.

84 Para las causas del boicot de la MPEAA a Dinamarca, ver GUBACK, T: op.cit, 1969, p. 42.

85 ACME-5562.
} 
Durante la década de los cuarenta las importaciones de películas norteamericanas experimentaron constantes altibajos y graves irregularidades que perjudicaron por igual a los dos grandes protagonistas de la transacción, el gobierno español y la MPEAA. Tras el intento de 1945-46, la tirantez de las relaciones bilaterales retrasó la escenificación de nuevas conversaciones. Las cosas fueron cambiando en paralelo al progresivo acercamiento bilateral provocado por la creciente polarización mundial, evidente a partir de 1950. Después de la exclusión de todos los organismos internacionales que iban a estructurar al bloque occidental, el régimen franquista apostó por sellar su legitimación exterior mediante un acuerdo bilateral con Estados Unidos, que a su vez deseaba integrar la península ibérica en su estrategia defensiva. Para reforzar esa tendencia el gobierno español interpretó que debía colaborar en lo posible a favorecer un clima de mayor sintonía. Las transacciones cinematográficas aparecieron como una oportunidad de ofrecer un gesto de buena voluntad al «amigo americano». La MPEAA detectó la oportunidad de obtener mejores condiciones para la importación de sus productos, por lo que reclamó una colaboración activa de su gobierno, que además compartía el interés por la exhibición de películas como parte de su política cultural exterior. Ante el interés del gobierno norteamericano, los diplomáticos españoles y probablemente el propio Franco decidieron negociar.

En España, como en buena parte de Europa, los sectores gubernamentales implicados en las importaciones se venían concentrando en sus efectos negativos, principalmente dos: salida de divisas y competencia al cine nacional. La corrupción y especulación generadas por los sistemas de importación y fomento de la producción reforzaron esos enfoques. Ello explica en buena medida la disposición contraria a los intereses norteamericanos de los primeros negociadores. El relevo de ese primer equipo, en consonancia con los intereses globales en juego, palió determinadas actitudes abiertamente contrarias a satisfacer los deseos de la corporación norteamericana en perjuicio de la economía y la industria nacional. En el otro bando, el protagonismo del embajador Griffis escenificó la cumbre de la colaboración interesada entre la MPEAA y su gobierno en relación a España. La coordinación de la presión económica generada por el boicot de operaciones de las casas norteamericanas, anunciado por el propio embajador en mayo de 1951, con las amenazas de un hipotético efecto reflejo sobre las incipientes negociaciones entre los dos estados, precipitaron la firma del primer convenio cinematográfico bilateral en enero de 1952. A pesar de su denominación, el acuerdo no hacía sino estipular un contrato comercial entre una corporación privada y un estado soberano.

Las disputas competenciales y las encontradas reacciones al acuerdo evidenciaron que, al menos en la delegación española, las tensiones generadas no iban a relajarse tras el convenio. Una vez esfumado el interés propagandístico por la firma del acuerdo, los gestores de la cinematografía nacional se sintieron con 
mayor libertad para tratar de paliar los efectos negativos que, se intuía, podían acaecer sobre la economía y la industria cinematográfica de entrar el vigor el acuerdo. Los cambios de personal volvieron a marcar la pauta a seguir. Ante el asombro norteamericano, los españoles tomaron el timón y se dedicaron a echar por tierra lo pactado, retrasando en medio año el inicio del convenio y aplicándolo en tal forma que la mayoría de las compañías norteamericanas no pudieron participar de él hasta pasados varios meses. Griffis había partido de España y el gobierno norteamericano, que ya había cumplido con la corporación, estaba concentrado en campos más trascendentales de la relación bilateral. Por si fuera poco, lo cierto es que las maniobras españolas se apoyaban en una estricta interpretación de la letra del convenio, lo que dejó a la defensiva a los norteamericanos. La cuerda se tensó enormemente, aunque los españoles nunca pretendieron romperla, o mejor dicho, desde el Ministerio de Comercio nunca se quiso romper. Cuando la situación parecía insostenible un nuevo cambio de personal devolvió la actitud dialogante y las buenas intenciones a la delegación española. La delegación norteamericana tomó nota.

A lo largo de las conversaciones de 1953 los norteamericanos endurecieron su posición hasta el punto de que el máximo encargado de la política comercial española, el ministro de Comercio, llegó a lanzar un farol en toda regla que acabaría retirando al poco tiempo. La cercanía de los convenios de septiembre de 1953 y la atmósfera de amistad bilateral que le siguió presentó a la MPEAA la oportunidad de retomar la iniciativa. En esta ocasión la corporación impuso unas condiciones mucho más perniciosas para las posiciones españolas, tomando cuerpo en el segundo convenio cinematográfico bilateral de noviembre de 1953. De nuevo, la presión provocada por la coyuntura bilateral había forzado la retirada española. Sin embargo, al igual que en 1952, los españoles no estaban dispuestos a cumplir su parte del trato, como demostrarían a la primera oportunidad.

A finales de 1954 el gobierno español consideró que era hora de forzar un cambio drástico en la relación con la MPEAA. La atmósfera de exaltación de la amistad bilateral se había relajado. Por si fuera poco, se podía prever que el gobierno norteamericano iba a desentenderse de unas enrevesadas negociaciones que, al fin y al cabo, sólo podían enturbiar la privilegiada posición obtenida en septiembre de 1953. En ese contexto, las disputas competenciales y las tensiones administrativas por el control de la política cinematográfica y por la dirección de las negociaciones, despertaron nuevamente con toda su virulencia. En esta ocasión, Información y Turismo se llevó el gato al agua, lo que implicaba que desde la Jefatura del Estado se veía con buenos ojos y se asumían las consecuencias de un cambio de actitud (sobre todo, teniendo en cuenta que hacía un par de meses la corporación había demostrado en Dinamarca que no estaba por la labor de ceder un ápice en sus conquistas). El margen de maniobra de los gestores de la cinematografía española era pues el más amplio desde 1950. Por el contrario, el margen de la MPEAA se había reducido enorme- 
mente: su gobierno no daba señales de querer inmiscuirse en una nueva disputa; mientras que el boicot de importaciones podía no alcanzar la misma efectividad que en años anteriores ante la mayor oferta de producciones y película virgen europeas.

La ofensiva del Ministerio de Información y Turismo iba a concluir con la ruptura de relaciones y el establecimiento por la MPEAA de un previsible boicot en agosto de 1955. La apuesta negociadora de la corporación había descansado sobre una coyuntura bilateral con fecha de caducidad, algo que iba a pagar: el silencio de la embajada norteamericana confirmó hasta donde llegaba su compromiso con las negociaciones. Probablemente, la propia inercia de la política negociadora de la corporación y el temor a nuevos «órdagos» en Europa, condujeron al boicot. En los años que siguieron a 1955, la presión comercial iba a mostrarse claramente insuficiente para doblegar al gobierno español.

En suma, las negociaciones desarrolladas entre 1950 y 1955 fueron complejas y muy conflictivas, aunque el flujo de películas nunca se cortó. La diversidad de actores y factores en juego, la caótica situación de la economía y la industria cinematográfica española y la coyuntura bilateral marcaron el rumbo. El comportamiento de la administración franquista evidenció descoordinación y cierta improvisación. Las disputas competenciales e individuales y los cambios de personal refuerzan una imagen que contribuye a desmitificar el pregonado monolitismo del régimen. En clave norteamericana, el caso español viene a delimitar la frontera de la colaboración durante la Guerra Fría entre una de las corporaciones más influyentes y cuestionadas del país y su gobierno, así como a resaltar la escasa flexibilidad y limitada efectividad de la agresiva estrategia negociadora de la MPEAA. 